\title{
Impact of COVID-19 on health behaviours and body weight: A prospective observational study in a cohort of 1.1 million UK and US individuals
}

Mohsen Mazidii

King's College London

Emily Leeming

King's College London

Jordi Merino

Harvard Medical School

Long Nguyen

Massachusetts General Hospital and Harvard Medical School

Somesh Selvachandran

Zoe Global

Tyler Maher

King's College London

Kirstin Kadé

Zoe Global

Benjamin Murray

King's College London

Mark Graham

King's College London https://orcid.org/0000-0002-4170-1095

Carole Sudre

King's College London

Jonathan Wolf

Zoe Global

Christina Hu

Zoe Global

David Drew

Massachusetts General Hospital and Harvard Medical School

Claire Steves

King's College London

Sebastien Ourselin

King's College London

Christopher Gardner 
Stanford Prevention Research Center,

\section{Tim Spector}

King's College London

\section{Andrew Chan}

Harvard Medical School

\section{Paul Franks}

Lund University Diabetes Center

\section{Rachel Gibson}

King's College London

Sarah Berry ( $\sim$ sarah.e.berry@kcl.ac.uk)

King's College London

\section{Article}

Keywords: coronavirus, physical activity, sleep, nutrition, eating behaviours, social isolation, diet

Posted Date: February 9th, 2021

DOl: https://doi.org/10.21203/rs.3.rs-179013/v1

License: (1) (1) This work is licensed under a Creative Commons Attribution 4.0 International License. Read Full License

Version of Record: A version of this preprint was published at Nature Food on December 16th, 2021. See the published version at https://doi.org/10.1038/s43016-021-00398-3. 


\section{Impact of COVID-19 on health behaviours and body weight: A prospective observational study in a cohort of 1.1 million UK and US individuals}

Mohsen Mazidi1 ${ }^{1, \# \#(0000-0003-3059-229 X), ~ E m i l y ~ R . ~ L e e m i n g ~}{ }^{1 \#}(0000-0002-0531-4901)$, Jordi Merino ${ }^{2,3,4}$ (0000-0001-8312-1438), Long H. Nguyen ${ }^{12,13}(0000-0002-5436-4219)$,

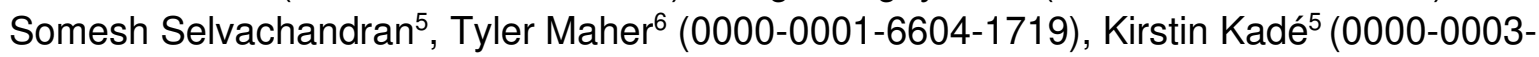
4072-9712), Benjamin Murray ${ }^{7}$, Mark S. Graham (0000-0002-4170-1095) ${ }^{7}$, Carole H. Sudre ${ }^{7,10,11}$, Jonathan Wolf ${ }^{5}$ (0000-0002-0530-2257), Christina Hu ${ }^{5}$, David A. Drew ${ }^{12,13}(0000-$ 0002-8813-0816), Claire J. Steves ${ }^{1}$, Sebastien Ourselin ${ }^{7}$, Christopher Gardner ${ }^{14}$ (00000002-7596-1530), Tim D. Spector ${ }^{1,5^{\wedge *}}$, Andrew T. Chan ${ }^{3,9,12,13^{\wedge}}$, Paul W. Franks ${ }^{8,9^{\wedge}}(0000-$ 0002-0520-7604), Rachel Gibson ${ }^{{ }^{\wedge}}(0000-0002-5823-6468)$, Sarah Berry ${ }^{6,,^{\wedge *}}(0000-0002-$ 5819-5109)

${ }^{1}$ Department of Twin Research, King's College London, SE1 7EH, London UK

2 Diabetes Unit and Center for Genomic Medicine, Massachusetts General Hospital, MA, 02115, USA

${ }^{3}$ Department of Medicine, Harvard Medical School, Boston, MA, 02115, USA

${ }^{4}$ Programs in Metabolism and Medical \& Population Genetics, Broad Institute, Cambridge, MA, 02142, USA

${ }^{5}$ Zoe Global Ltd, London, SE1 7RW, UK

${ }^{6}$ Department of Nutritional Sciences, King's College London, London, SE1 9NH, UK

${ }^{7}$ School of Biomedical Engineering \& Imaging Sciences, King's College London, London, SE1 9NH, UK

${ }^{8}$ Lund University Diabetes Center, Department of Clinical Sciences, Lund University, Malmö, SE-214 28, Sweden

${ }^{9}$ Harvard T.H. Chan School of Public Health, Boston, MA, 02115, USA

${ }^{10} \mathrm{MRC}$ Unit for Lifelong Health and Ageing at UCL, University College London, WC1E 7HB, London UK

${ }^{11}$ Centre for Medical Image Computing, University College London, London UK

${ }^{12}$ Clinical and Translational Epidemiology Unit, Massachusetts General Hospital and Harvard Medical School, Boston, MA, 02114, USA

${ }^{13}$ Division of Gastroenterology, Massachusetts General Hospital and Harvard Medical School, Boston, MA, 02114, USA

${ }^{14}$ Stanford Prevention Research Center, Stanford University Department of Medicine, Stanford, CA, 94305

\footnotetext{
\# These authors contributed equally

${ }^{\wedge}$ These authors jointly supervised this work

*Corresponding author: Sarah Berry (sarah.e.berry@kcl.ac.uk) and Tim Spector (tim.spector@kcl.ac.uk)
} 


\section{Abstract}

2 Evidence regarding the impact of COVID-19 on health behaviours is limited. In this 3 prospective study including 1.1 million UK and US participants we collected diet and

4 lifestyle data 'pre- 'and 'peri- 'pandemic, and computed a bi-directional health

5 behaviour disruption index. We show that disruption was higher in the younger,

6 female and socioeconomically deprived $(p<0.001)$. A loss in body weight $(-0.45 \mathrm{~kg})$

7 was greater in highly disrupted individuals compared to those with low disruption (-

$8 \quad 0.03 \mathrm{~kg}$ ). There were large inter-individual changes observed in all 46 health and diet

9 behaviours measured peri-pandemic versus pre-pandemic, but no mean change in

10 the total population. Individuals most adherent to unhealthy pre-pandemic health

11 behaviours improved their diet quality (0.93units) and weight $(-0.79 \mathrm{~kg})$ compared

12 with those reporting healthy pre-pandemic behaviours $(0.08$ units and $-0.04 \mathrm{~kg}$

13 respectively), irrespective of relative deprivation. For a proportion of the population,

14 the pandemic may have provided an impetus to improve health behaviours.

\section{$15 \quad$ Funding}

16 Zoe Global, Wellcome Trust, DHSC

18 Keywords: coronavirus, physical activity, sleep, nutrition, eating behaviours, social

19 isolation, diet

21 Abbreviations: ZOE COVID Symptom Study (ZCSS); United Kingdom (UK); United

22 States of America (US); Mobile Application (app); Disruption Index (DI); Diet Quality 
23 Score (DQS); Food Frequency Questionnaire (FFQ); Body Mass Index (BMI); (SEM)

24 Structural equation modelling; (IMD) Index of Multiple Deprivation Introduction:

Mandatory public health initiatives to control and limit COVID-19 disease spread have led to dramatic changes in day-to-day routines, resulting in increased social isolation ${ }^{1,2}$, employment and financial insecurities ${ }^{3}$, and an altered food environment ${ }^{4}$. This is placing most of the world's population in a unique global experiment on a massive scale. Small European-based studies have observed exacerbation of unfavourable diet and lifestyle behaviours attributable to these changes such as increased sedentary behaviour, more snacking, less fresh food consumption and weight gain, although the published data are inconclusive ${ }^{5-7}$.

At an individual level, significant life events are associated with changes in health behaviours such as alcohol intake ${ }^{8}$, sleep ${ }^{9,10}$, diet ${ }^{11,12}$ and physical activity ${ }^{13}$. The complex interrelation of these health behaviours potentially mediates increases in body weight observed during adulthood ${ }^{14-16}$, impacting the number of adults living with excess weight and consequent morbidities ${ }^{17-20}$, which is a significant public health threat ${ }^{21}$. Therefore, understanding how health behaviours change in the context of a pro-longed pandemic is critical to understanding its long-term consequences, and to inform short- and long-term strategies to prevent excess weight gain.

In a prospective observational cohort study of 1.1 million participants from the ZOE COVID Symptom Study (ZCSS) we: i) describe the self-reported impact of the

47 COVID-19 pandemic on diet and health behaviours using a composite disruption 
index, ii) determine the association of diet and lifestyle behaviours with weight change during the pandemic, and iii) explore the relationship between pre-pandemic behavioural patterns and change in specific diet and lifestyle behaviours.

52 There were large inter-individual changes observed in all 46 health and diet

53 behaviours measured peri-pandemic versus pre-pandemic, but no mean change was observed in the total population. Individuals most adherent to unhealthy prepandemic diet and health behaviours were more inclined to improve their overall diet quality and lose weight, irrespective of relative deprivation, whilst those most adherent to healthy pre-pandemic behaviours exhibited little change in health behaviours. Disruption of health behaviours resulting from the pandemic was higher in the younger, female, and socioeconomically deprived segment of the population. However, a greater disruption was associated with a more variable change in weight and greater weight loss compared to less disrupted individuals, suggesting that the disruption resulted in a more favourable diet and lifestyle change for a proportion of people. Structural equation modelling revealed that changes in physical activity and diet quality during the pandemic were the most relevant factors associated with weight change.

67 Our data provide quantitative evidence about the impact of the COVID-19 pandemic on lifestyle behaviours, and indicate that the perceived negative impact of the pandemic on health behaviours and factors that exacerbate this, may not hold true 22. Indeed, the pandemic may have provided the impetus to improve many diet and lifestyle behaviours amongst a large proportion of the population. 
74 Results

Characteristics of participants responding to the diet and lifestyle survey

A detailed dataset from 1.1 million respondents: Within the ZCSS, we launched a

diet and lifestyle longitudinal, observational cohort study (United Kingdom (UK)

31/07/2020 to 25/09/2020, United States of America (US) 25/09/2020 to 30/11/2020)

concurrent with other ongoing ZCSS investigations. For this study, participants were

invited to complete a retrospective diet and lifestyle questionnaire (see Methods) assessing diet quality, diet habits, and lifestyle behaviours at two time points; (1) 'peri-pandemic', described as the previous month from participant access, and (2) 'pre-pandemic'described as the month of February 2020. Baseline participant characteristics including demographics and comorbidities were also assessed from the ZCSS ${ }^{23}$. For UK data, an Index of Multiple Deprivation (IMD) was assigned to participants as a surrogate measure of deprivation. IMD provides an estimate of relative deprivation across several domains (including income, employment, and education) by geographical region ${ }^{24}$.

After exclusion of pregnant women, incomplete questionnaires, and implausible data (see Methods), data were available for $n=909,096$ peri-pandemic and $n=310,565$ pre- and peri- pandemic participants. The characteristics of the participants who completed the diet and lifestyle survey peri-pandemic are summarised in Table 1,

94 Supplemental Table 1 and 2. Compared to the average UK population, UK participants who completed the diet and lifestyle survey were older (mean age 52 vs 41 years respectively), had a lower BMI (25 vs $27 \mathrm{~kg} / \mathrm{m}^{2}$ respectively), resided in less deprived areas (for IMD range 8-10: 41 vs $30 \%$ and for IMD range 1-3: 10 vs $30 \%$ 
98 respectively) and were less likely to smoke. The UK proportion of males and non-

99 white UK ethnicities was also lower amongst surveyed participants versus the

100 general population (33 vs $49 \%$ and 4 vs $14 \%$ respectively). The proportions of

101 respondents across geographical regions in the UK were broadly similar to the UK

102 population distribution. A similar pattern was observed for the US cohort (Table 1

103 and Supplemental Table 1).

104

105 Prior to data analysis, the UK cohort was divided into discovery $(n=425,657)$ and

106 validation $(n=422,285)$ sets, owing to slight differences in data collection processes

107 (see Methods and Supplemental Table 2). Data from 61,154 participants from the

108 US were used as an independent replication cohort (see Methods).

109 
Table 1. Characteristics of app users; all UK participants, and from whom pre- and peripandemic data are included in analyses.

\begin{tabular}{|c|c|c|c|c|c|}
\hline & $\begin{array}{c}\text { All UK } \\
\text { participants } \\
(\mathrm{n}=847,942)^{*}\end{array}$ & $\begin{array}{c}\text { UK Discovery } \\
\text { cohort } \\
(n=207,722)^{\star \#}\end{array}$ & $\begin{array}{c}\text { UK Validation } \\
\text { cohort } \\
(\mathrm{n}=76,868)^{\star} \#\end{array}$ & $\begin{array}{r}\text { US Replic } \\
\text { cohor } \\
(n=14,3\end{array}$ & $\begin{array}{l}\text { cation } \\
\text { rt } \\
66)^{\#}\end{array}$ \\
\hline \multicolumn{6}{|c|}{ Basic characteristics } \\
\hline $\begin{array}{l}\text { Male/Female } \\
\text { Age (Y) }\end{array}$ & $\begin{array}{c}33.4 / 66.5 \% \\
52(40,62)\end{array}$ & $\begin{array}{l}31.0 / 68.9 \% \\
58(48,66)\end{array}$ & $\begin{array}{l}24.0 / 76.0 \% \\
50(39,59)\end{array}$ & \multicolumn{2}{|c|}{$\begin{array}{l}17.5 / 82.4 \% \\
61(47,68)\end{array}$} \\
\hline Weight (kg) & $\begin{array}{c}73.4 \\
(63.9,85)\end{array}$ & $\begin{array}{c}72.0 \\
(63.0,84.3)\end{array}$ & $\begin{array}{c}74.3 \\
(64.8,87.0)\end{array}$ & \multicolumn{2}{|c|}{$\begin{array}{c}74.7 \\
(64.3,88.3)\end{array}$} \\
\hline BMI $\left(\mathrm{kg} / \mathrm{m}^{2}\right)$ & $\begin{array}{c}25.3 \\
(22.8,28.7)\end{array}$ & $\begin{array}{c}25.1 \\
(22.7,28.5)\end{array}$ & $\begin{array}{c}26.1 \\
(23.3,30.0)\end{array}$ & \multicolumn{2}{|c|}{$\begin{array}{c}26.6 \\
(23.5,31.0)\end{array}$} \\
\hline Smokers & $3.0 \%$ & $2.1 \%$ & $2.9 \%$ & \multicolumn{2}{|c|}{$3.0 \%$} \\
\hline \multicolumn{6}{|l|}{ Ethnicity } \\
\hline $\begin{array}{l}\text { Asian } \\
\text { Black }\end{array}$ & $\begin{array}{l}1.4 \% \\
0.3 \%\end{array}$ & $\begin{array}{l}0.8 \% \\
0.2 \%\end{array}$ & $\begin{array}{l}1.6 \% \\
0.4 \%\end{array}$ & \multicolumn{2}{|c|}{$\begin{array}{l}3.8 \% \\
3.2 \%\end{array}$} \\
\hline Chinese & $0.3 \%$ & $0.2 \%$ & $0.4 \%$ & \multirow{2}{*}{$\begin{array}{l}\text { Native } \\
\text { American } \\
\text { Native } \\
\text { Hawaiian }\end{array}$} & $1.3 \%$ \\
\hline $\begin{array}{l}\text { Middle } \\
\text { Eastern }\end{array}$ & $0.3 \%$ & $0.2 \%$ & $0.4 \%$ & & $0.4 \%$ \\
\hline White & $95.8 \%$ & $97.1 \%$ & $95.1 \%$ & \multicolumn{2}{|l|}{88.4} \\
\hline Mixed other & $1.0 \%$ & $0.8 \%$ & $1.2 \%$ & \multicolumn{2}{|l|}{-} \\
\hline $\begin{array}{l}\text { Mixed } \\
\text { white/black }\end{array}$ & $0.4 \%$ & $0.3 \%$ & $0.4 \%$ & \multicolumn{2}{|l|}{-} \\
\hline Other & $0.3 \%$ & $0.4 \%$ & $0.5 \%$ & \multicolumn{2}{|l|}{1.6} \\
\hline \multicolumn{6}{|l|}{ Preconditions } \\
\hline Diabetes & $3.1 \%$ & $3.8 \%$ & $2.9 \%$ & \multicolumn{2}{|c|}{$5.2 \%$} \\
\hline $\begin{array}{l}\text { Heart } \\
\text { disease }\end{array}$ & $2.9 \%$ & $3.8 \%$ & $2.5 \%$ & \multicolumn{2}{|c|}{$6.0 \%$} \\
\hline $\begin{array}{l}\text { Kidney } \\
\text { disease }\end{array}$ & $0.8 \%$ & $0.9 \%$ & $0.7 \%$ & \multicolumn{2}{|c|}{$1.8 \%$} \\
\hline \multicolumn{6}{|l|}{ UK location } \\
\hline England & $80.7 \%$ & $80.8 \%$ & $81.2 \%$ & \multicolumn{2}{|l|}{-} \\
\hline Scotland & $5.4 \%$ & $5.3 \%$ & $5.5 \%$ & \multicolumn{2}{|l|}{-} \\
\hline Wales & $4.7 \%$ & $4.5 \%$ & $4.6 \%$ & \multicolumn{2}{|l|}{-} \\
\hline $\begin{array}{l}\text { Northern } \\
\text { Ireland }\end{array}$ & $0.6 \%$ & $0.5 \%$ & $0.6 \%$ & \multicolumn{2}{|l|}{-} \\
\hline \multicolumn{6}{|c|}{ Index of multiple deprivation } \\
\hline $1-3$ & $10.2 \%$ & $8.7 \%$ & $10.9 \%$ & \multicolumn{2}{|l|}{-} \\
\hline $4-7$ & $34.6 \%$ & $34.2 \%$ & $35.5 \%$ & \multicolumn{2}{|l|}{ - } \\
\hline $8-10$ & $40.5 \%$ & $42.4 \%$ & $39.4 \%$ & \multicolumn{2}{|l|}{-} \\
\hline
\end{tabular}

113 Application of a novel lifestyle Disruption Index

114 A novel disruption index revealed that lifestyle disruption resulting from the 
116 lifestyle disruption attributable to the pandemic, we computed a novel disruption

117 index (DI) including 5 metrics; Diet Quality Score ${ }^{25}$, alcohol frequency, physical

118 activity, snacking frequency (food consumed outside of main meals) and weekday

119 sleep duration (see Methods). These domains were selected to capture the primary

120 diet and lifestyle behaviours associated with multiple health outcomes including

121 obesity ${ }^{26-31}$. The DI was independent of direction of change, ranged from 0 (no

122 disruption) to 5 (change in all five health behaviour domains) and approximated a

123 normal distribution (Figure 1a). In the UK discovery cohort, most participants

124 experienced a moderate level of disruption (65.5\%; DI $\geq 2$ ), while $15 \%$ had a high

125 level of disruption ( $\mathrm{DI} \geq 4$ ). The $\mathrm{DI}$ (Figure 1a) was different (chi-squared) according

126 to sex $(P<0.001$, effect size: 0.119$)$, age category ( $P<0.001$, effect size: 0.274$)$,

127 assigned level of deprivation $(P<0.001$, effect size: 0.066$)$, and geographical location

$128(\mathrm{P}<0.001$, effect size $=0.018)$; with a greater $\mathrm{DI}$ among younger individuals, females

129 and people living in more deprived areas. Similar patterns for age and sex was

130 observed for the US replication cohort. Participant characteristics according to the DI

131 scores, for the UK and US are detailed in Supplementary Table 3.

A greater disruption is associated with a larger bi-directional change in weight:

134 The mean overall change in body weight was small in the UK discovery cohort;

135 mean change $\left(10^{\text {th }}, 90^{\text {th }}\right.$ percentile $)$ was $-0.1(-4.1,3.6) \mathrm{kg}$. However, weight change

136 was highly variable among individuals, with $32 \%$ of participants losing a mean body

137 weight of $-4.0 \mathrm{~kg}\left(10^{\text {th }}\right.$ centile; $-8.2,90^{\text {th }}$ centile; -0.9$)$ and $34 \%$ gaining a mean body

138 weight of $3.5 \mathrm{~kg}\left(10^{\text {th }}\right.$ centile; $0.9,90^{\text {th }}$ centile; 6.3$)$ during the pandemic

139 (Supplemental Table 4). A similar pattern and magnitude of change was also

140 observed for the US replication cohort (Supplemental Table 4). Owing to the 
141 marked bi-directional weight change in the study population, we separately examined associations according to weight change, loss and gain.

144 When we analysed the association between the DI and body weight change, we

145 observed a more pronounced and variable weight change (both loss and gain)

146 among individuals with a high DI (CV; UK discovery cohort; 1355\%, US; 1750\%)

147 compared with those with a low DI (CV; UK discovery cohort; 1142\%, US; 1531\%);

148 Figure 1b, Supplemental Table 3. Weight loss and gain in the high DI group (mean

$149\left(10^{\text {th }}, 90^{\text {th }}\right.$ percentile $\left.)\right)$ was $-5.2(-10.9,-1.0) \mathrm{kg}$ and $4.0(1.0,8.0) \mathrm{kg}$ respectively,

150 compared with $-3.2(-6.3,-0.6) \mathrm{kg}$ and $3.1(0.5,5.4) \mathrm{kg}$ respectively in the low DI group (all $p<0.001$ ). A similar pattern and magnitude of weight loss and gain was observed in the US according to DI (Supplemental Table 3).

154 In the UK, we showed that the DI was associated with weight changes after adjusting

155 for potential confounders (age and sex) in which the association was similar but of 156 greater magnitude among individuals living in areas with low deprivation (IMD; 8-10, 157 B $-0.041,95 \% \mathrm{Cl}:-0.194,-0.137)$ compared with high deprivation (IMD; 1-3, ß -0.024, 95\% Cl: $0 .-13,-0.057)$. When stratified according to DI groups and deprivation index,

159 there was a similar magnitude of weight loss between levels of deprivation, but a

160 moderately higher weight gain in the UK group residing in more deprived areas

$161(4.4 \mathrm{~kg})$ versus the group in less deprived areas $(3.8 \mathrm{~kg})$ within the highly disrupted group (Supplemental Table 3). This observation suggests that community-level deprivation factors may not impair the potential positive behavioural effects of

164 disruption, but may also exacerbate the negative effects to a small extent, with 165 individuals living in more deprived areas being more susceptible to weight gain. 

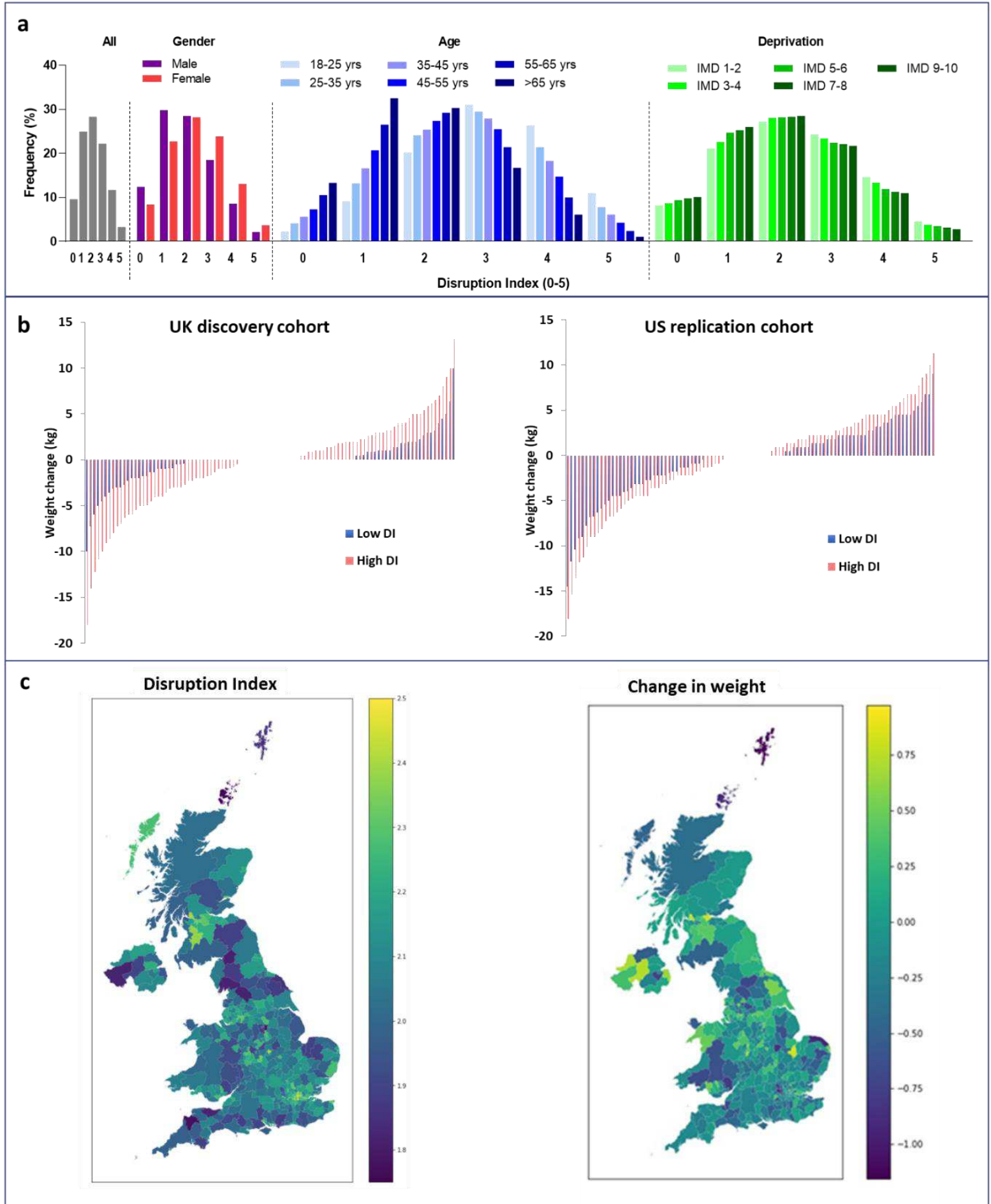

168 Figure 1. Disruption Index population distribution and weight change.

169 a. Community-level disruption Index on a scale of $0-5$ including 5 domains (Diet Quality

170 Score, snacking frequency, alcohol intake frequency, physical activity and weekday sleep 171 duration), stratified according to sex, age and multiple deprivation index based on residence 
172 (IMD) in the UK cohort. b. Change in body weight during the pandemic (pre minus peri-

173 pandemic values) stratified according to low $(\leq 1)$ or high $(\geq 4)$ disruption index in the UK

174 discovery and US replication cohort. c. Geographical distribution of disruption index and 175 change in weight in the UK discovery cohort.

177 Physical activity and diet quality are important determinants of weight gain

178 during the pandemic: We next examined the association of changes in the 5

179 lifestyle behaviour domains captured by the DI and age $\mathrm{e}^{32}$, with body weight change

180 (bi-directional) using structural equation modelling (Figure 4a and $\mathbf{d}$ ). For individuals

181 who gained weight during the pandemic, a reduction in physical activity, diet quality,

182 and an increase in alcohol intake and snacking were moderately associated with

183 weight gain. Among individuals who lost weight during the pandemic, contrasting

184 associations were observed. This trend remained when examined within strata of

185 community level deprivation (Supplemental Table 5), Figure 4b, c, e and f;

186 although the effect size was slightly greater in individuals residing in more deprived

187 areas. Therefore, in accordance with most population based strategies, our results

188 show that diet quality and physical activity are the most promising targets to prevent

189 weight gain across all socioeconomic classes during a global pandemic.

190

191 

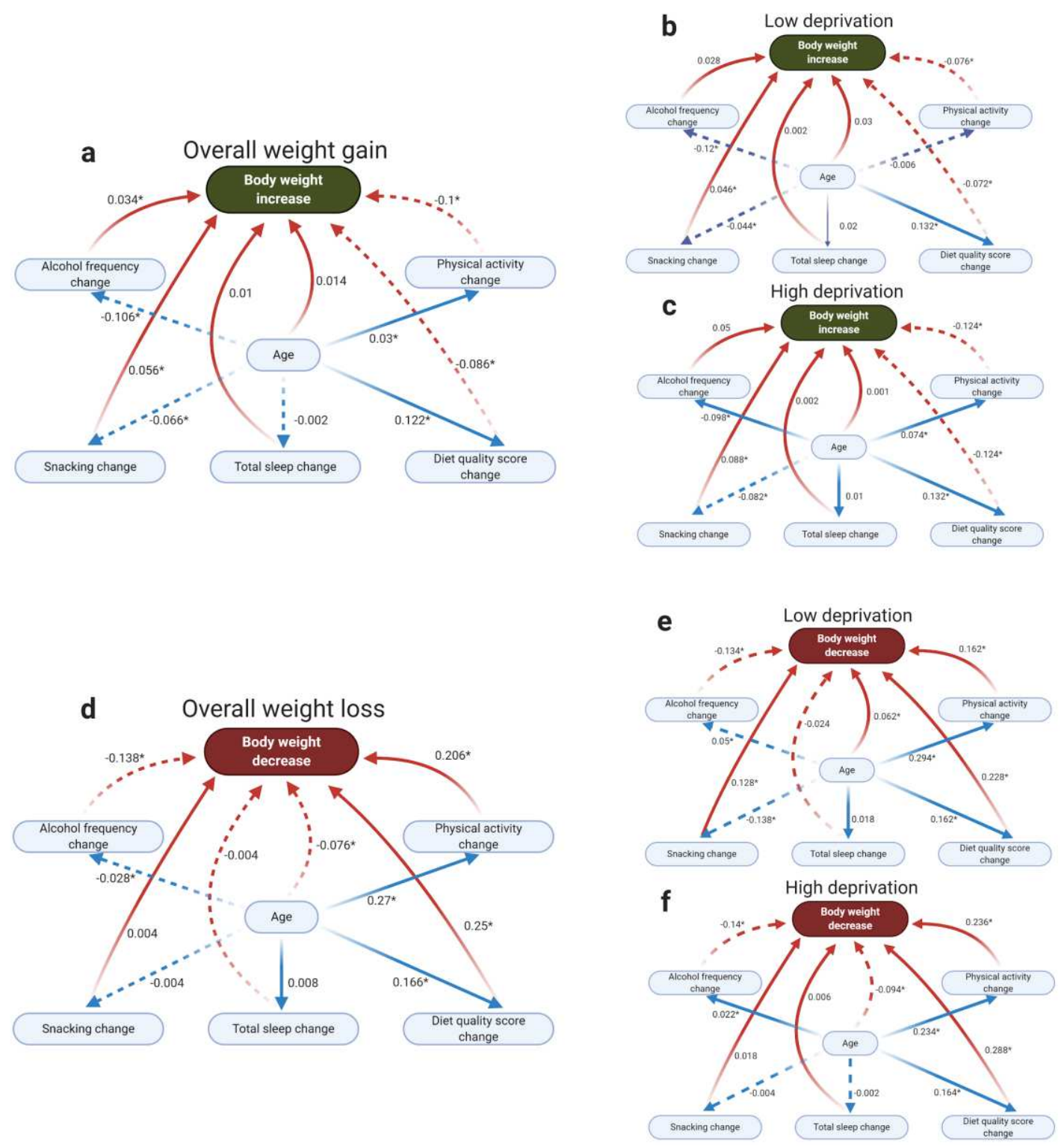

193 Figure 2. Association between diet and lifestyle and change in weight pre- to peri-

194 pandemic. Structural equation modelling (SEM) showing the associations between exposures identified by machine learning and outcome (body weight increase/decrease). a. overall increase, b. body weight increase in the high IMD (IMD8-10) sub-population, c. body

197 weight increase in the low IMD (IMD1-3) sub-population, d. overall decreased body weight,

198 e. body weight decrease in high IMD (IMD8-10) sub-population, f. body weight decrease in 199 low IMD (IMD1-3) sub-population. Blue arrows represent indirect effects on body weight.

200 Red arrows represent direct effects on body weight. Dashed arrows represent inverse 
effects on body weight. Numbers represent strength of association (standardised B coefficients). *significant at $\mathrm{P}<0.05$. Full dataset seen in Supplementary Table 5.

Changes in separate lifestyle, dietary habits and diet quality pre- and peripandemic

There was no mean change in the total population, but large individual level changes in lifestyle, diet habits and diet quality: To assess the changes in individual exposure variables that contribute to the disruption and weight change caused by the pandemic, we next explored the direction of change in the different

210 health behaviours measured, pre- and peri-pandemic (Table 2 and Figure 3a and b,

211 Supplemental Table 4, 6 and 7). In accordance with the negligible average change

212 in weight across the population, there was minimal average change in all diet and

213 lifestyle variables in response to the pandemic (in the UK and US). However, when

214 assessed according to the proportion of individuals who increased or decreased

215 specific lifestyle behaviour, the magnitude of the change was larger. For example, in

216 the UK discovery cohort, although there was overall minimal mean change in the

217 Diet Quality Score (mean $\left(10^{\text {th }}\right.$ and $90^{\text {th }}$ percentile $\left.)\right)(0.3(-2.0,2.0))$, more

218 participants increased their score $(39 \%$ by a mean of $1.8(1.0,3.0)$ than decreased

219 (26\% by a mean of $-1.7(-3.0,-1.0)$. Likewise, a higher proportion of participants

$220(32.5 \%)$ increased daily fruit and vegetable portions (by mean 2.1 (1.0, 5.0), from 3.5

$221(0.0,6.0)$ to $5.6(3.0,8.0)$ portions/d) than decreased $(22.7 \%)$ (by mean $-1.7(-3.0,-$ 1.0), from $5.6(3.0,8.0)$ to $3.8(1.0,7.0)$ portions/d), consistent with a level that would confer significant health effects ${ }^{27,33}$. There was also only a minimal mean change in

224 the number of snacks consumed per day (by mean $-0.1(-1.0,1.0)$, but a large number of individuals increased (18\%) (by mean 1.4 snacks/d $(1.0,2.0)$ (from 
$2261.0 / \mathrm{d})$ ) and decreased (22\%) (by mean -1.3 snacks/d (-2.0, -1.0) (from 2.5/d)). More

227 people increased their weekday sleep (15\%) than decreased (9\%) although the

228 magnitude of change was similar (mean $+/-1.2 \mathrm{hrs}$ ). Interestingly, for frequency of

229 alcohol intake, the proportion of people increasing (18.4\%) was greater than the

230 proportion decreasing (11.2\%), whilst the inverse was the case for the amount at

231 each drinking event (10.7\% increasing vs $13.5 \%$ decreasing units); suggesting that

232 total amount of alcohol (frequency $\mathrm{x}$ units) consumption may have been unchanged.

233 Notably, most participants reported no change (92.8\%) in food access, likely a

234 reflection of the survey demographic, although more participants reported a

235 decrease in food access (5.8\%) versus an increase (1.4\%).

236

237 A similar pattern of change in the individual variables was observed in the UK

238 validation cohort and US replication cohort, with the exception of physical activity

239 levels. In the UK the proportion of participants increasing and decreasing their

240 physical activity was similar (in both cohorts) yet in the US the proportion of

241 participants decreasing their physical activity (35.6\%) was greater than those

242 increasing (24.1\%) (Table 2 and Figure 3). The moderately greater magnitude of

243 change in the UK validation and US replication cohorts versus the UK discovery

244 cohort is likely a consequence of the different data collection methods (see

245 Methods). All other variables from the questionnaire, including full FFQ data, are

246 reported for pre- and peri-pandemic, as well as the change, in Supplementary

247 Tables 4, 6 and 7. 
Table 2. Pre- and peri-pandemic data, percentage increase/decrease, and size of change

\begin{tabular}{|c|c|c|c|c|c|c|c|}
\hline & \multicolumn{3}{|c|}{ Averaged data } & \multicolumn{2}{|c|}{ Increase } & \multicolumn{2}{|c|}{ Decrease } \\
\hline & $\begin{array}{c}\text { Pre- } \\
\text { pandemic }\end{array}$ & $\begin{array}{c}\text { Peri- } \\
\text { pandemic }\end{array}$ & $\begin{array}{c}\text { Change } \\
\left(10^{\text {th }}, 90^{\text {th }}\right)\end{array}$ & $\begin{array}{c}\text { Participants } \\
(\%)\end{array}$ & $\begin{array}{c}\text { Change } \\
\left(10^{\text {th }}, 90^{\text {th }}\right)\end{array}$ & $\begin{array}{c}\text { Participants } \\
(\%)\end{array}$ & $\begin{array}{c}\text { Change } \\
\left(10^{\text {th }}, 90^{\text {th }}\right)\end{array}$ \\
\hline \multicolumn{8}{|c|}{ UK Discovery cohort } \\
\hline \multicolumn{8}{|l|}{ Anthropometrics } \\
\hline Weight $(\mathrm{kg})$ & $74.9(15.8)$ & $74.8(15.6)$ & $-0.1(-4.1,3.6)$ & 34.0 & $3.5(0.9,6.3)$ & 32.0 & $-4.0(-8.2,-0.9)$ \\
\hline $\mathrm{BMI}\left(\mathrm{kg} / \mathrm{m}^{2}\right)$ & $26.0(4.3)$ & $25.9(4.3)$ & $-0.04(-1.5,1.2)$ & 34.0 & $1.1(0.3,2.3)$ & 32.0 & $-1.3(-2.9,-0.3)$ \\
\hline \multicolumn{8}{|l|}{ LSFFFQ Diet questionnaire } \\
\hline Diet quality score & $10.8(1.8)$ & $11.1(1.8)$ & $0.3(-2.0,2.0)$ & 39.0 & $1.8(1.0,3.0)$ & 26.0 & $-1.7(-3.0,-1.0)$ \\
\hline Fruit Portions & $2.0(1.3)$ & $2.1(1.3)$ & $0.2(-1.0,1.0)$ & 24.0 & $1.5(1.0,3.0)$ & 15.0 & $-1.3(-2.0,-1.0)$ \\
\hline Vegetable portions & $2.5(1.3)$ & $2.7(1.3)$ & $0.1(-1.0,1.0)$ & 23.0 & $1.6(1.0,3.0)$ & 17.0 & $-1.4(-2.0,-1.0)$ \\
\hline Glasses of juice & $0.3(0.6)$ & $0.3(0.6)$ & $0.02(0.0,0.0)$ & 8.0 & $1.3(0.5,3.0)$ & 6.0 & $-1.3(-3.0,-1.0)$ \\
\hline \multicolumn{8}{|l|}{ Activity behaviours } \\
\hline Weekdays sleep (h) & $7.0(1.0)$ & $7.0(0.9)$ & $0.1(0.0-1.0)$ & 15.0 & $1.2(1.0,2.0)$ & 9.0 & $-1.2(-2.0,-1.0)$ \\
\hline Weekends sleep (h) & $7.4(1.1)$ & $7.3(1.0)$ & $-0.04(-1.0-0.0)$ & 8.0 & $1.2(1.0,2.0)$ & 11.0 & $-1.2(-2.0,-1.0)$ \\
\hline \multicolumn{8}{|l|}{ Eating behaviour } \\
\hline Number of main meals $\#$ & $1.9(0.7)$ & $1.9(0.6)$ & $0.04(0.0,0.0)$ & 7.0 & $1.4(1.0,2.0)$ & 6.0 & $-1.1(-2.0,-1.0)$ \\
\hline Numbers of snacks & $1.6(1.1)$ & $1.5(1.0)$ & $-0.1(-0.1,1.0)$ & 18.0 & $1.4(1.0,2.0)$ & 22.0 & $-1.3(-2.0,-1.0)$ \\
\hline Eats breakfast (\%) & 80.6 & 83.4 & 2.8 & - & - & - & - \\
\hline Worried about control $(\%)^{\dagger}$ & 15.2 & 18.4 & 3.3 & - & - & - & - \\
\hline \multicolumn{8}{|c|}{ UK Validation cohort } \\
\hline \multicolumn{8}{|l|}{ Anthropometrics } \\
\hline Weight $(\mathrm{kg})$ & $77.1(16.5)$ & $77.2(16.2)$ & $0.1(-6.3,5.9)$ & 49.0 & $4.1(1.0,7.7)$ & 36.0 & $-5.2(-10.4,-1.0)$ \\
\hline $\operatorname{BMI}\left(\mathrm{kg} / \mathrm{m}^{2}\right)$ & $27.1(5.4)$ & $27.2(5.4)$ & $0.1(-2.2,2.0)$ & 49.0 & $1.5(0.4,2.7)$ & 36.0 & $-1.8(-3.7,-0.4)$ \\
\hline \multicolumn{8}{|l|}{ LSFFFQ Diet questionnaire } \\
\hline Diet quality score & $10.5(1.9)$ & $10.9(1.9)$ & $0.4(-2.2,3.0)$ & 44.0 & $2.2(1.0,4.0)$ & 30.0 & $-1.9(-3.0,-1.0)$ \\
\hline Fruit Portions & $1.8(1.3)$ & $2.0(1.2)$ & $0.2(-1.0,2.0)$ & 32.0 & $1.5(1.0,3.0)$ & 21.0 & $-1.3(-2.0,-1.0)$ \\
\hline Vegetable portions & $2.4(1.4)$ & $2.7(1.3)$ & $0.3(-1.0,2.0)$ & 31.0 & $1.7(1.0,3.0)$ & 19.0 & $-1.3(-2.0,-1.0)$ \\
\hline Glasses of juice & $0.3(0.6)$ & $0.3(0.6)$ & $0.02(0.0,0.5)$ & 11.0 & $1.2(0.5,2.0)$ & 8.0 & $-1.3(-2.0,-0.5)$ \\
\hline \multicolumn{8}{|l|}{ Activity behaviours } \\
\hline Weekdays sleep (h) & $6.9(1.0)$ & $7.0(1.0)$ & $0.1(-1.0,1.0)$ & 33.0 & $1.2(1.0,2.0)$ & 14.0 & $-1.3(-2.0,-1.0)$ \\
\hline Weekends sleep (h) & $7.5(1.2)$ & $7.4(1.1)$ & $-0.1(-1.0,1.0)$ & 24.0 & $1.3(1.0,2.0)$ & 18.0 & $-1.3(-2.0,-1.0)$ \\
\hline \multicolumn{8}{|l|}{ Eating behaviour } \\
\hline Number of main meals $\#$ & $1.9(0.7)$ & $2.0(0.6)$ & $0.1(0.0,1.0)$ & 12.0 & $1.4(1.0,2.0)$ & 9.0 & $-1.0(-1.0,-1.0)$ \\
\hline Numbers of snacks & $1.8(1.2)$ & $1.8(1.1)$ & $0.0(-2.0,2.0)$ & 30.0 & $1.5(1.0,2.0)$ & 31.0 & $-1.5(-2.0,-1.0)$ \\
\hline Eats breakfast (\%) & 73.9 & 78.3 & 4.4 & - & - & - & - \\
\hline Worried about control $(\%)^{\dagger}$ & 26.6 & 36.3 & 9.7 & - & - & - & - \\
\hline \multicolumn{8}{|c|}{ US Replication cohort } \\
\hline \multicolumn{8}{|l|}{ Anthropometrics } \\
\hline Weight $(\mathrm{kg})$ & $77.8(17.5)$ & $77.5(17.2)$ & $-0.3(-6.8,5.0)$ & 44.0 & $3.8(0.9,7.7)$ & 39.0 & $-5.0(-10.4,-0.9)$ \\
\hline $\mathrm{BMI}\left(\mathrm{kg} / \mathrm{m}^{2}\right)$ & $27.8(5.9)$ & $27.8(5.8)$ & $-0.1(-2.3,1.8)$ & 44.0 & $1.4(0.3,2.7)$ & 39.0 & $-1.8(-3.7,-0.4)$ \\
\hline \multicolumn{8}{|l|}{ LSFFFQ Diet questionnaire } \\
\hline Diet quality score & $10.8(1.7)$ & $10.5(1.7)$ & $0.3(-0.2,3.0)$ & 41.0 & $2.0(1.0,4.0)$ & 29.0 & $-1.7(-3.0,-1.0)$ \\
\hline Fruit Portions & $1.5(1.1)$ & $1.7(1.1)$ & $0.2(-1.0,1.0)$ & 29.0 & $1.4(1.0,2.0)$ & 18.0 & $-1.2(-2.0,-1.0)$ \\
\hline Vegetable portions & $2.0(1.4)$ & $2.3(1.3)$ & $0.3(-1.0,2.0)$ & 30.0 & $1.7(1.0,3.0)$ & 20.0 & $-1.3(-2.0,-1.0)$ \\
\hline Glasses of juice & $0.2(0.6)$ & $0.3(0.6)$ & $0.02(0.0,0.0)$ & 9.0 & $1.3(0.5,3.0)$ & 8.0 & $-1.2(-2.0,-0.5)$ \\
\hline \multicolumn{8}{|l|}{ Activity behaviours } \\
\hline Weekdays sleep (h) & $7.0(1.0)$ & $7.0(1.0)$ & $0.1(-1.0,1.0)$ & 20.0 & $1.2(1.0,2.0)$ & 15.0 & $-1.3(-2.0,-1.0)$ \\
\hline Weekends sleep (h) & $7.6(1.2)$ & $7.5(1.1)$ & $-0.05(-1.0,1.0)$ & 13.0 & $1.3(1.0,2.0)$ & 16.0 & $-1.3(-2.0,-1.0)$ \\
\hline \multicolumn{8}{|l|}{ Eating behaviour } \\
\hline Number of main meals" & $2.0(0.8)$ & $1.8(1.0)$ & $0.03(-1.0,1.0)$ & 11.0 & $1.6(1.0,3.0)$ & 14.0 & $-1.1(-1.0,-1.0)$ \\
\hline Numbers of snacks & $1.8(1.2)$ & $2.0(0.6)$ & $0.1(-1.0,1.0)$ & 27.0 & $1.4(1.0,2.0)$ & 25.0 & $-1.3(-2.0,-1.0)$ \\
\hline Eats breakfast (\%) & 73.0 & 76.9 & 3.9 & - & - & - & - \\
\hline Worried about control $(\%)^{\dagger}$ & 20.5 & 33.7 & 13.2 & - & - & - & - \\
\hline
\end{tabular}


a

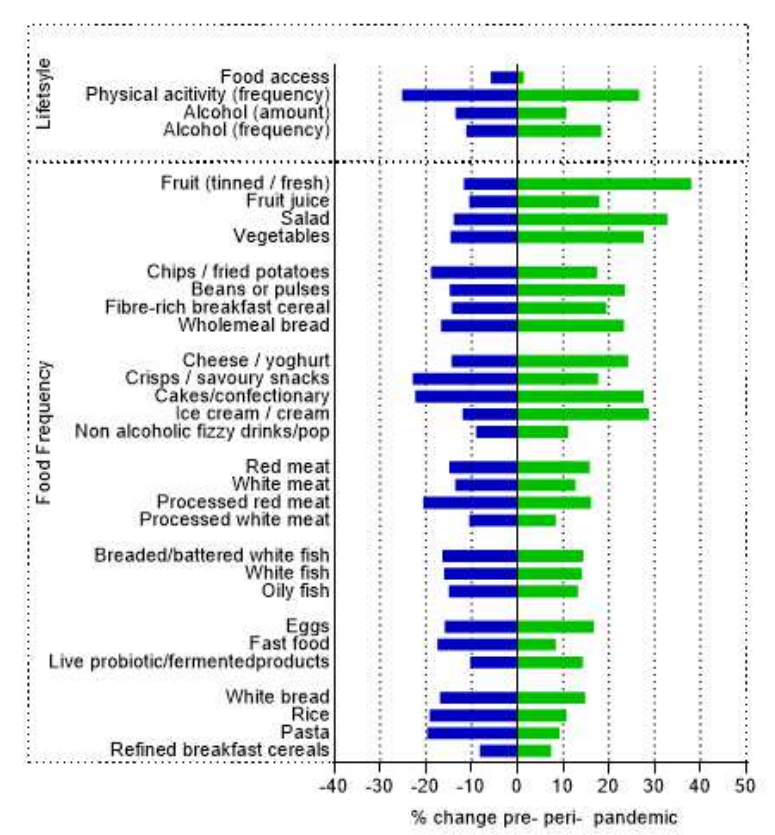

b UK validation cohort

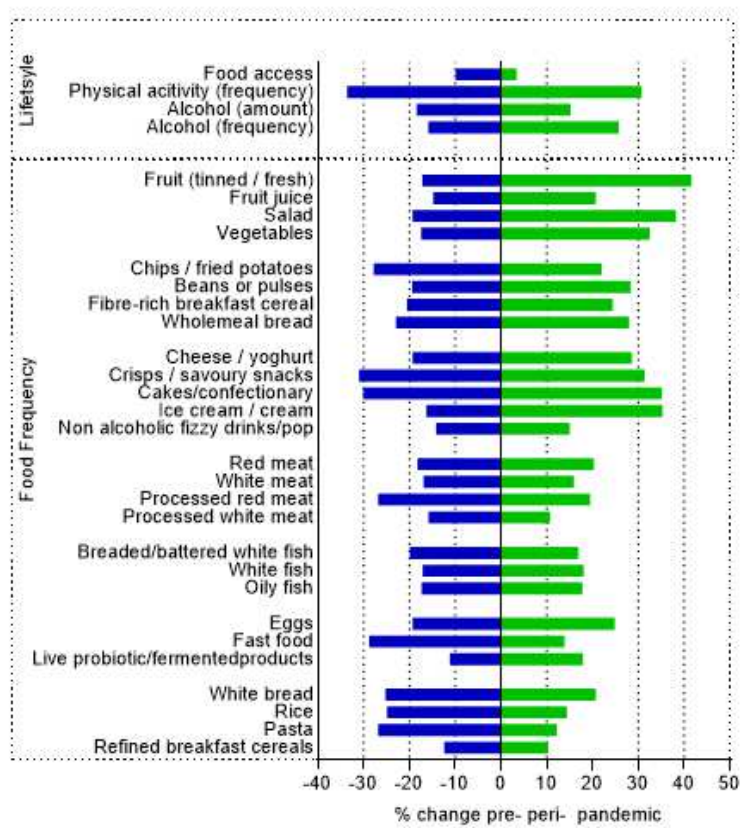

c US replication cohort

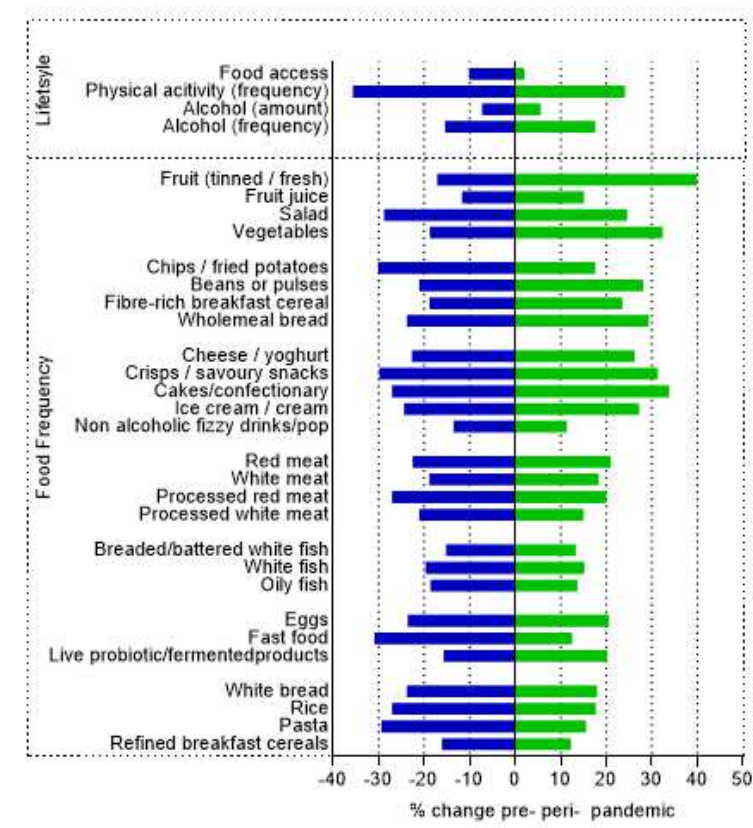

Figure 3. Proportion of the population changing frequency of intake of food groups and behaviours. Percentage of cohort that changed (increase/decreased) the frequency of dietary intake and lifestyle behaviours from pre- to peri-pandemic, obtained from the amended Leeds Short Form Food Frequency Questionnaire and others, in the a) UK discovery b) UK validation and c) US replication cohorts. 


\section{An unfavourable pre-pandemic diet and lifestyle behaviour is associated with}

258 improved changes to diet and lifestyle: To explore the impact of pre-pandemic

259 diet and lifestyle behaviours on the variable response to the pandemic reported

260 above, we undertook a factor analysis (see Methods). Two distinct diet and lifestyle

261 patterns were identified and labelled as a 'healthy 'and an 'unhealthy 'pattern based

262 on items and loadings summarised in Figure 4 and Supplementary Table 8 . The

263 'healthy 'pattern was characterised by lower intakes of alcohol, fast food and

264 processed meats, a higher intake of cheese and fibre-rich cereals and higher levels

265 of physical activity. The 'unhealthy 'pattern differed, with a lower Diet Quality Score,

266 lower intakes of fruit and vegetable portions, higher intakes of crisps, savoury

267 snacks, sweets, biscuits and processed meats, and lower levels of physical activity

268 generally observed. A broadly similar pattern was displayed in the US replication

269 cohort, albeit with increased emphasis on salad and oily fish for the 'healthy 'pattern

270 and fast food for the 'unhealthy 'pattern. 


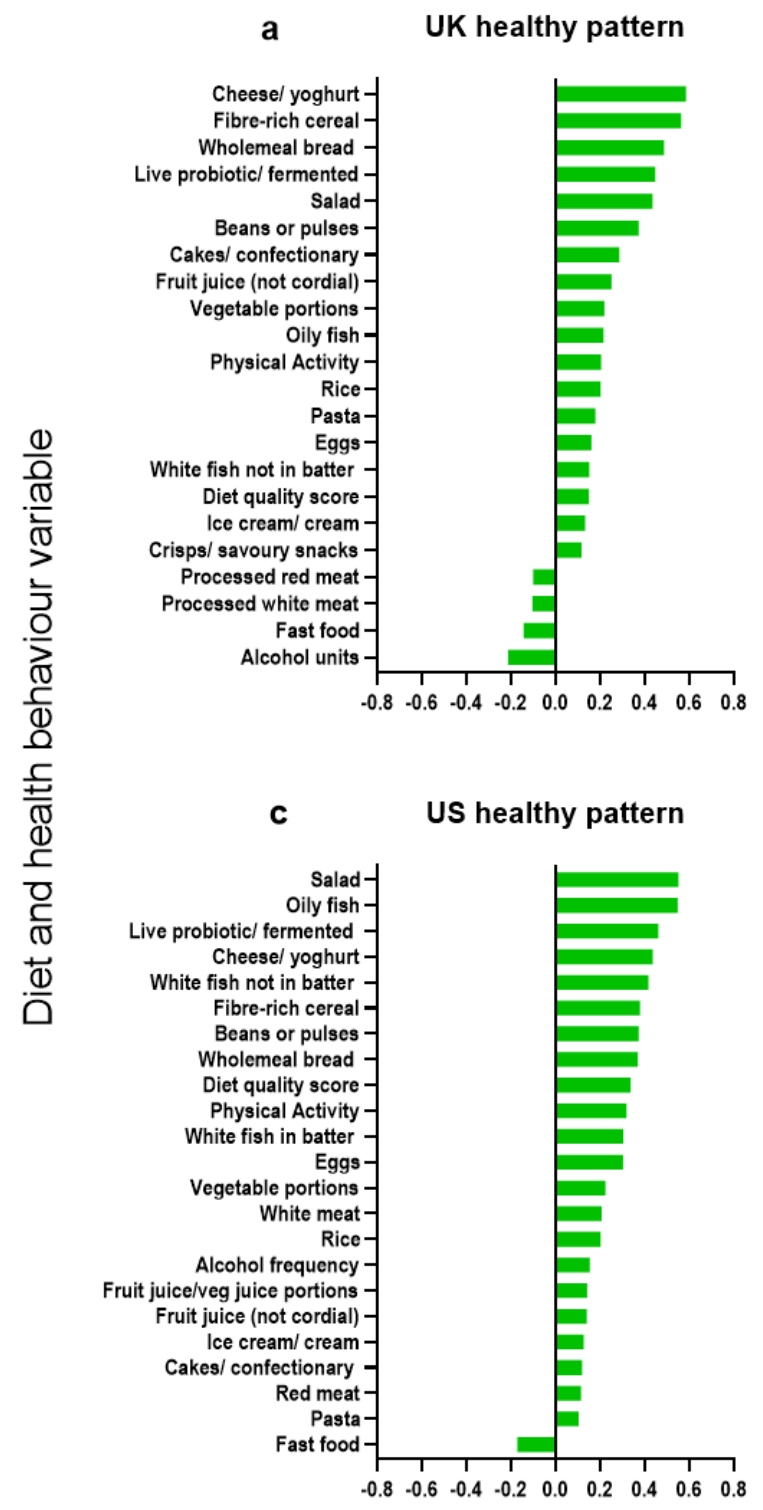

Loading factor
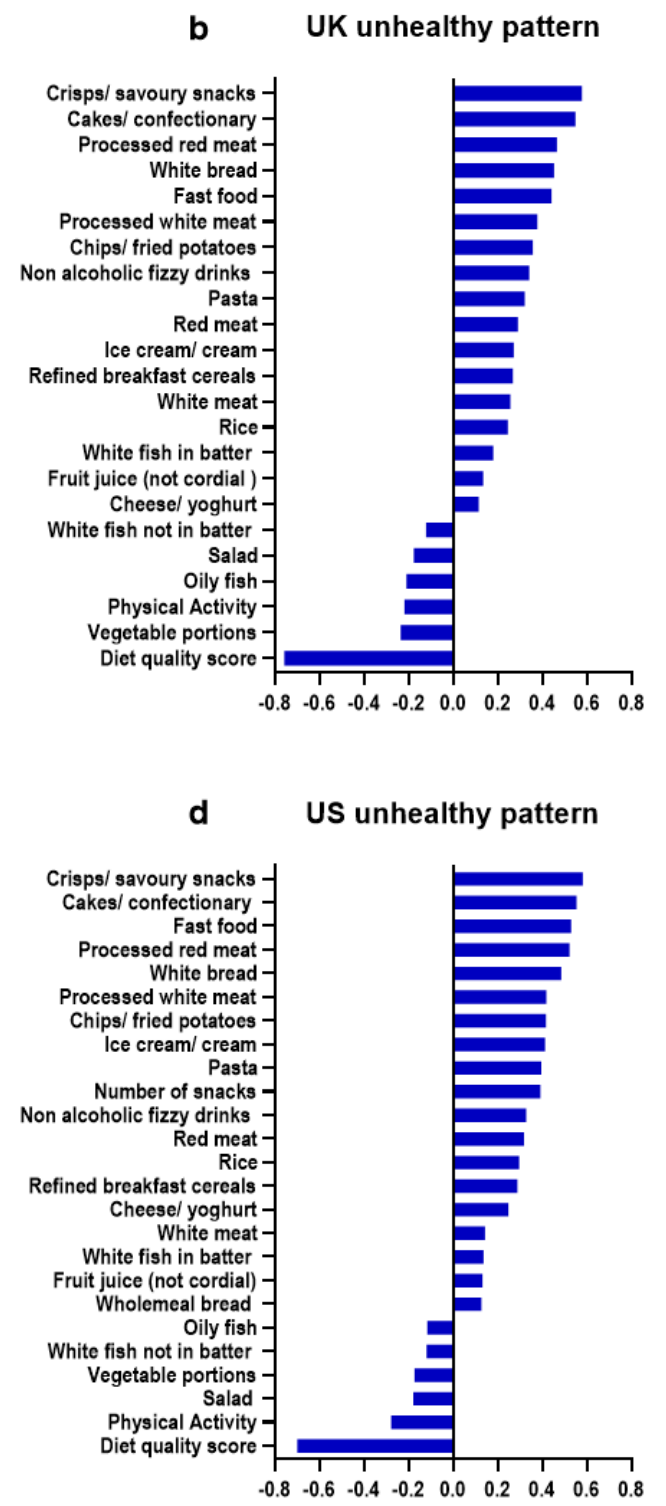

Loading factor

273 clusters. Loadings ( $\geq 0.1)$ for 'healthy '(a) and 'unhealthy '(b) patterns in the UK discovery

274 and 'healthy '(c) and 'unhealthy '(d) patterns in the US replication cohort. Full breakdown of

275 the loading of each dietary and health behaviour variable for the 'healthy 'and 'unhealthy '

276 pattern can be seen in Supplementary Table 8.

278 We observed differences in participant's demographic and behavioural characteristics 
280 For example, in the UK, those with the highest adherence to the 'healthy 'pattern (Q4

281 vs Q1) were on average older (61 vs 56 years), more likely to be female (73 vs 62

$282 \%)$, less likely to smoke (0.8 vs $4.1 \%$ ) and more likely to reside in an area with a

283 lower level of deprivation (44.6 vs 40.5 with IMD 8-10) than those with the least

284 adherence (all $p<0.001$ ) (Table 3). The reverse pattern was observed for those most

285 and least adherent to the 'unhealthy 'pattern. A broadly similar pattern was observed

286 in the US replication cohort (Supplementary Table 9).

288 We next examined the association between pre-pandemic diet and lifestyle

289 behaviours with the peri-pandemic change in health behaviours. We found that

290 individuals most adherent to the 'unhealthy 'pre-pandemic lifestyle pattern lost more

291 weight than those reporting higher adherence to the 'healthy 'lifestyle pattern (by

$2921.1 \mathrm{~kg}$ ) (Table 3). The same trends of association were also observed in other diet

293 and lifestyle measures; with a larger increase in Diet Quality Score, fruit and

294 vegetable consumption and a larger decrease in the number of snacks among those

295 most adherent to the 'unhealthy 'pattern compared with the 'healthy 'lifestyle pattern.

296 These findings suggest that participants with unhealthy behaviours in the pre-

297 pandemic phase were more likely to implement healthy changes. This may be a

298 consequence of a greater scope for improvement in the 'unhealthy 'group, whilst

299 those classified as having a healthy pre-pandemic lifestyle pattern, tended to retain

300 their 'beneficial 'health behaviours and experienced minimal change. This

301 observation was also reflected in the lower DI in those highly adherent to the

302 'healthy 'pattern and the higher DI in those adherent to the 'unhealthy 'pattern (both

$303 \mathrm{p}<0.001)$. A similar pattern of response was observed in the US replication cohort,

304 but with a greater magnitude of favourable change in those most adherent to the 
305 unhealthy lifestyle, possibly due to minimal differences in data collection (see

306 Methods).

308 To assess if the population demographics were driving this finding, in the UK, we

309 stratified individuals most adherent to the 'unhealthy 'pattern according to their

310 community-level deprivation, age, sex and geographical location. When stratified

311 according to deprivation (IMD 1-3 vs 8-10), the improvement in diet quality (0.91 vs

3120.92 units respectively) and reduction in body weight ( $-0.5 \mathrm{vs}$. $-0.8 \mathrm{~kg}$ respectively)

313 remained, although attenuated. Age, sex and country also had only a small impact

314 on the change in weight (aged 18-25 yrs; -1.1 vs. aged >65 yrs; -0.6 kg; male -1.1

315 vs. female $-0.6 \mathrm{~kg}$; England -0.8 vs. Wales -0.8 vs. Scotland -0.7 vs. Northern

316 Ireland -0.9 all kg) and minimal impact on diet quality score (aged 18-25 yrs; 0.8 vs.

317 aged $>65$ yrs; 0.8 , England 0.9 vs. Wales 1.0 vs. Scotland 0.9 vs. Northern Ireland

318 0.7, all units). Therefore, irrespective of community-level deprivation, age, sex and

319 location, individuals most adherent to an 'unhealthy 'pre-pandemic pattern

320 experienced beneficial changes in diet quality and weight.

322 Taken together, our data suggest that the perceived negative impact of the

323 pandemic on diet and lifestyle behaviours may not hold true for all. 
Table 3. Characteristics and outcomes for upper and lower quartiles within 'Unhealthy' and 'Healthy' patterns, clustered using principal component analysis (PCA).

\begin{tabular}{|c|c|c|c|c|}
\hline \multicolumn{5}{|c|}{ UK Discovery cohort } \\
\hline & \multicolumn{2}{|c|}{ Unhealthy pattern } & \multicolumn{2}{|c|}{ Healthy pattern } \\
\hline & Q1 & Q4 & Q1 & Q4 \\
\hline \multicolumn{5}{|c|}{ Descriptives } \\
\hline \multicolumn{5}{|l|}{ Basic characteristics } \\
\hline Male/Female (\%) & $21.2 / 78.7$ & $39.8 / 60.1$ & $37.7 / 62.3$ & $27.5 / 72.5$ \\
\hline Age $(Y)$ & $61(53,68)$ & $53(43,62)$ & $56(46,64)$ & $61(52,67)$ \\
\hline Race: white & 97.5 & 97.3 & 97.0 & 97.7 \\
\hline Smokers & 1.2 & 2.8 & 4.1 & 0.8 \\
\hline \multicolumn{5}{|l|}{ Preconditions } \\
\hline Diabetes & 2.8 & 3.9 & 4.6 & 2.2 \\
\hline Heart disease & 3.4 & 3.1 & 3.8 & 3.4 \\
\hline Kidney disease & 0.7 & 0.9 & 0.9 & 0.7 \\
\hline \multicolumn{5}{|l|}{ UK location } \\
\hline England & 83.2 & 79.1 & 81 & 81 \\
\hline Scotland & 4.4 & 6.3 & 5.0 & 5.7 \\
\hline Wales & 3.7 & 5.1 & 5.1 & 4.1 \\
\hline Northern Ireland & 0.4 & 0.7 & 0.6 & 0.5 \\
\hline \multicolumn{5}{|c|}{ Index of multiple deprivation } \\
\hline $1-3$ & 7.2 & 9.8 & 10.6 & 6.5 \\
\hline $4-7$ & 35.0 & 34.1 & 34.9 & 33.8 \\
\hline $8-10$ & 44.7 & 40.4 & 40.5 & 44.6 \\
\hline \multicolumn{5}{|l|}{ Disruption Index } \\
\hline 0 & 13.3 & 5.7 & 8.4 & 11.1 \\
\hline 1 & 28.3 & 18.7 & 22 & 27.7 \\
\hline 4 & 8.8 & 17.2 & 14.2 & 10 \\
\hline 5 & 2.2 & 6 & 4.7 & 2.5 \\
\hline \multicolumn{5}{|c|}{ Changes } \\
\hline \multicolumn{5}{|l|}{ Anthropometrics } \\
\hline Weight $(\mathrm{kg})$ & $0.32(-3.0,3.6)$ & $-0.79(-6.2,3.6)$ & $-0.24(-5.2,4.1)$ & $-0.04(-3.2,3.0)$ \\
\hline \multicolumn{5}{|l|}{ Diet } \\
\hline Diet quality score & $-0.32(-2.0,1.0)$ & $0.93(-1.0,3.0)$ & $0.37(-1.0,2.0)$ & $0.08(-2.0,2.0)$ \\
\hline Fruit Portions & $-0.03(-1.0,1.0)$ & $0.13(-1.0,1.0)$ & $0.07(-1.0,1.0)$ & $0.01(-1.0,1.0)$ \\
\hline Vegetable portions & $-0.09(-1.0,1.0)$ & $0.11(-1.0,1.0)$ & $0.04(-1.0,1.0)$ & $-0.03(-1.0,1.0)$ \\
\hline \multicolumn{5}{|l|}{ Eating behaviour } \\
\hline Number of snacks & $0.04(-1.0,1.0)$ & $-0.34(-2.0,1.0)$ & $-0.13(-1.0,1.0)$ & $-0.11(-1.0,1.0)$ \\
\hline \multicolumn{5}{|c|}{ US replication cohort } \\
\hline & \multicolumn{2}{|c|}{ Unhealthy pattern } & \multicolumn{2}{|c|}{ Healthy pattern } \\
\hline & Q1 & Q4 & Q1 & Q4 \\
\hline \multicolumn{5}{|l|}{ Basic characteristics } \\
\hline Male/Female (\%) & $12.1 / 87.9$ & $23.2 / 76.7$ & $18.5 / 81.4$ & $18.6 / 81.3$ \\
\hline $\operatorname{Age}(\mathrm{Y})$ & $63(53,69)$ & $43(57,67)$ & $54(40,66)$ & $63(54,69)$ \\
\hline Race: white & 91.6 & 89.9 & 90.1 & 90.0 \\
\hline Smokers & 1.7 & 4.3 & 4.4 & 1.6 \\
\hline \multicolumn{5}{|l|}{ Preconditions } \\
\hline Diabetes & 3.0 & 5.8 & 5.0 & 3.1 \\
\hline Heart disease & 5.4 & 5.8 & 5.0 & 5.5 \\
\hline Kidney disease & 0.9 & 1.5 & 1.7 & 1.5 \\
\hline & & Changes & & \\
\hline Anthropometrics & & & & \\
\hline Weight (kg) & $1.0(-3.6,5.4)$ & $-2.0(-9.5,4.5)$ & $-0.7(-8.2,5.0)$ & $-0.1(-5.4,4.5)$ \\
\hline Diet & & & & \\
\hline Diet quality score & $-0.53(-2.0,1.0)$ & $1.16(-1.0,4.0)$ & $0.54(-1.0,3.0)$ & $-0.12(-2.0,2.0)$ \\
\hline Fruit Portions & $-0.07(-1.0,1.0)$ & $0.22(-1.0,1.0)$ & $0.15(-1.0,1.0)$ & $-0.03(-1.0,1.0)$ \\
\hline Vegetable portions & $-0.19(-1.0,1.0)$ & $0.27(-1.0,2.0)$ & $0.18(-1.0,1.0)$ & $-0.07(-1.0,1.0)$ \\
\hline Eating behaviour & & & & \\
\hline Number of snacks & $0.21(-1.0,1.0)$ & $-0.43(-2.0,1.0)$ & $-0.12(-1.0,1.0)$ & $-0.04(-1.0,1.0)$ \\
\hline
\end{tabular}




\section{Discussion}

329 The COVID-19 pandemic could be viewed as a unique natural experiment with a

330 major lifestyle disruptor impacting key health behaviours associated with longer-term

331 health outcomes, both at individual-level and for populations as a whole. In this

332 study, using data collected through the largest survey of diet and lifestyle during the

333 pandemic to date, we have described the impact of the pandemic on lifestyle

334 behaviour changes in large samples of the UK and US populations. Through the application of a novel Disruption Index, this study highlights the disruptive nature of

336 the pandemic on health behaviours, which was associated with a higher and more

337 variable bi-directional change in body weight. The magnitude of weight loss $(-5.2 \mathrm{~kg})$

338 was greater than the weight gain $(4.0 \mathrm{~kg})$ in more disrupted individuals, whilst less

339 disrupted individuals experienced no difference in the magnitude of weight loss (-

$3403.2 \mathrm{~kg}$ ) or gain $(3.1 \mathrm{~kg})$. The health behaviours of females, younger participants and

341 those residing in more deprived areas were the most disrupted during this time

342 period of the pandemic. This observation is a likely consequence of unpaid care and

343 family responsibilities falling disproportionately to women, particularly younger

344 females (26-35 years), with women over-represented in lower-income households ${ }^{34}$.

345 Although we observed no mean changes in diet and lifestyle behaviours in the total

346 population, upon stratifying the data, considerable inter-individual variation exists.

347 This variability in the response of individual health behaviours to COVID-19 is in

348 agreement with studies exploring the impact of comparable mandatory public health

349 interventions across Europe. The EHLC-COVID19 project in Italy (3,533 participants)

350 observed no mean change in diet or lifestyle habits due to lockdown in $46.1 \%$ of

351 respondents, but a perceived weight gain reported by $58.6 \%$ and a slight increase in

352 physical activity reported by $38.3 \%$ of study participants ${ }^{6}$. Findings from the NutriNet- 
353 Sante cohort in France (37,252 participants, surveyed over 2-months) showed a

354 weight gain in a comparable percentage of the population sample (35\%) with an average weight gain of $+1.8 \mathrm{~kg}$. However, this study observed a lower incidence of weight loss ( $23 \%$ of respondents), with a $-2 \mathrm{~kg}$ average loss compared to our

357 findings ${ }^{35}$.

358 Most surprisingly, those participants who were identified to have an 'unhealthy '

359 pattern pre-pandemic were more likely to experience improvements in diet quality and greater weight loss peri-pandemic, irrespective of deprivation status. Whilst this may reflect some bias due to the users of the app being self-selected and typically of a higher socio-economic demographic than the UK and US average citizen, the NutriNet-Sante study also observed that positive health behaviour changes were associated with less healthy pre-pandemic behaviours ${ }^{36}$. These findings suggest that the pandemic may not have had the detrimental impact on diet and lifestyle behaviours for a significant proportion of the population, as had previously been speculated and reported in the media 37,38 .

368 Excess body weight has been linked with an increase of COVID-19 severity ${ }^{39,40}$ and 369 chronic disease mortality ${ }^{41}$, and is known to be interrelated with social determinants 370 of health, including systematic racism ${ }^{42}$, and disparities in food security and socioeconomic status ${ }^{43,44}$. Bi-directional weight changes were observed between groups stratified by levels of deprivation, with those reporting unhealthy behaviours residing in more deprived areas experiencing more weight gain than for those residing in less deprived areas. However, irrespective of deprivation, physical activity and diet quality were identified as key determinants of both short-term weight gain and loss. Mean change in body weight for those who experienced an increase $(3.5 \mathrm{~kg}, \mathrm{SD} 5.1 \mathrm{~kg})$ or 
377 decrease $(-4.0 \mathrm{~kg}$, SD $4.8 \mathrm{~kg})$ in weight was significant and greater than typical daily

378 body weight fluctuations of $1-2 \mathrm{~kg}^{45}$. While definitions of clinically significant weight

379 change are not consistent within the literature, $>5 \%$ decrease in body weight has

380 been associated with improved metabolic function ${ }^{46}$. Follow-up investigations are

381 required to determine if body weight changes are maintained in the long-term and

382 associated with corresponding improvements in metabolic health.

383 Whilst this study had multiple strengths including sample size, an independent

384 replication cohort, and longitudinal data, we note several limitations. Firstly, the self-

385 reported nature of the data collected with the potential of recall bias with

386 retrospective data collection. Data collection methods were modified part way

387 through the study to minimise participant burden and decrease attrition (see

388 Methods). Although we observed no significant difference in baseline characteristics

389 of individuals who had their information collected prior to and after the change, a

390 sensitivity analysis displayed minimal population characteristic differences.

391 Therefore, the UK sample population was divided into a discovery and validation

392 cohort to reduce possible error.

393 Other limitations include the absence of data on change in smoking behaviour.

394 Additionally, the DI is a crude index designed to determine positive or negative

395 changes in each health behaviour domain, further work is needed to determine how

396 direction of change in the individual components may contribute to health outcomes.

397 Further, only 5 domains were included in the DI and 6 in the SEM, and therefore

398 other health behaviours associated with the pandemic disruption and subsequent

399 weight change are not accounted for. For example, we did not include level of

400 isolation, mental health or comorbidities due to time restraints on participant 
questionnaire completion. Other considerations such as job role and furlough status may also be relevant. This should be a consideration for future studies to assist in

403 interpretation of lifestyle behaviour change in response to COVID-19.

404 Regression to the mean can also be problematic in studies that focus on assessing 405 change in behaviours in subgroups of the population, such as ours, where only a 406 single follow-up assessment is made. This is because the assessment of health 407 behaviours is prone to error, and error tends to be greatest at the extremes of the 408 distribution of the variable being assessed, such as the most and least healthy participants. Thus, to some extent, the improvements in health behaviours seen in

410 people recording the most unhealthy behaviours at baseline could be artificial

411 improvements. Nevertheless, the same degree of change was not observed in 412 people who reported the most healthy baseline behaviours, which reinforces the argument that changes in health seen in either group are likely to be real.

415 In conclusion, rare and extreme events, such as the COVID-19 pandemic, could be 416 viewed as a major disruptor impacting key health behaviours associated with longer417 term health outcomes for populations. However, what becomes clear from this large 418 population-based study is that the pandemic has impacted individuals differently, 419 with those most disrupted being more susceptible to greater weight change.

420 Targeted approaches towards population groups more susceptible to unhealthy diet 421 and lifestyle behaviours as a result of future disruption may increase the 422 effectiveness of public health initiatives and minimise national and local expenditure. 423 Similarly, focused public health approaches that can support and expand on positive 424 health behaviour changes may be of value. 


\section{Study design and participants}

428 The ZOE COVID Symptom Study mobile application (ZCSS app) was developed by

429 the technology company ZOE in collaboration with King's College London, UK and

430 Massachusetts General Hospital, US. It was made available for free download for

431 Apple and Android users (UK 24/03/2020, US 29/03/2020). The application offers a

432 guided interface developed using Expo and ReactNative (JavaScript). Participants

433 were requested to report information including baseline demographics,

434 comorbidities, daily symptoms, and COVID-19 testing outcomes.

436 Using the ZCSS app, a longitudinal, observational cohort study investigating diet

437 quality, diet habits and lifestyle changes before and during the pandemic was

438 launched (UK 31/07/2020 to 25/09/2020, US 25/09/2020 to 30/11/2020). Participants

439 were recruited via the app interface. At enrolment, participants consented to the use

440 of their information for research investigations related to COVID-19, diet and lifestyle,

441 and to applicable privacy policies and terms of use. The study was approved by

442 Partners Human Research Committee (protocol 2020P000909) and King's College

443 London ethics committee (REMAS ID 18210; LRS-19/20-18210). The ZCSS app is

444 registered with ClinicalTrials.gov, NCT04331509. Data collected in the app are being

445 shared with other health researchers through the NHS-funded Health Data Research

446 UK (HDRUK)/SAIL Consortium, housed in the UK Secure e-Research Platform

447 (UKSeRP) in Swansea, Wales. Anonymized data are available to be shared with

448 bona fide researchers through HDRUK according to their protocols in the public

449 interest. U.S. investigators are encouraged to coordinate data requests through the

450 COPE Consortium (www.monganinstitute.org/cope-consortium). 
452 Information obtained through the ZCSS mobile application has been described in detail previously ${ }^{23,47}$. Participants were requested to complete a retrospective

454 questionnaire investigating diet quality, diet habits and lifestyle at two time points; (1)

455 'peri-pandemic', described as the previous month (from user access), (2) 'pre-

456 pandemic 'described as the month of February 2020. The sections contained

457 identical sets of questions collated by the research team and included the validated

458 Leeds Short Form Food Frequency Questionnaire (FFQ) ${ }^{25}$ developed by Cleghorn 459 and listed in the Nutritools (www.nutritools.org) library (Supplementary Document 460 App Flow).

461

462 Questionnaire Userface: The user experience was drafted in a requirements document by the engineering and product team at ZOE. A designer laid out a format optimised for mobile and tablet devices. The format and the requirements document were reviewed by the researchers. Answer options were developed using a library of standard form components, these included a dropdown list, multi-select checkboxes and user input validation. Interstitial pages provided guidance to the users on how to answer these questions. A prominent callout label displayed the time period at the top of every screen to remind users to 'Answer for the last 4 weeks 'or 'Answer for

470 the month of February 2020'.

472 Prior to launching, the release candidate of the app (including the questionnaire) was

473 circulated to internal quality assurance (QA) testers and nutrition researchers to 474 check the delivered software matched the requirements document. Sample data 475 collected from the QA sessions were reviewed and checked to be in an analysable 
476 format. The questionnaire was launched via controlled roll-out to a smaller cohort of

477 users before wider dissemination. Existing users were invited to complete the

478 questionnaire using a feature flag, which allows targeting of specific users before

479 roll-out to wider user base. 199,230 UK users, and 19,079 US users declined the diet

480 study invite in the app.

481

482 Participants were prompted to complete an additional consent form to allow

processing for data for purposes outside of COVID-19 research, to allow for further

484 investigations into diet and lifestyle aspects independent of COVID-19. As users

485 submit questionnaires to the application, data is submitted in JSON format to REST

486 APIs / WebServers that store the questionnaire response in a Postgres Database

487 that is hosted in Google Cloud Platform operated by ZOE. This data is anonymised

488 and exported daily into Comma Separated Value files that are delivered via Secure

489 FTP from ZOE to the researchers partners for further analysis.

490

491 The LSF-FFQ interface was developed by the engineering team in conjunction with

492 the designer using a $4 \times 2$ grid of the 8 FFQ 'frequency of consumption 'options. Effort

493 was made to retain the original structure and layout of the paper-based validated

494 LSF-FFQ ${ }^{25}$. The questionnaire was designed for participants to complete the first

495 section in reference to the previous four weeks (peri-pandemic), and then guided to

496 complete an identical section for the month of February 2020 (pre-pandemic).

497 Additional food items were included in the LSF-FFQ under general consensus by two

498 dietitians and a nutritionist. These food items included fast food, eggs and egg

499 dishes, refined carbohydrates such as white rice, white pasta and white bread, live 
500 probiotic or fermented foods such as kimchi, live yogurt and kefir (Supplementary

501 Document App Flow).

502

503 Data collection: Data was collected via two similar app flows in the UK (over an 8

504 week period), and via one app flow in the US (over a 9 week period). In the UK, the

505 questionnaire was released to $1 \%$ on $31 / 07 / 2020,2 \% 04 / 08 / 2020$, and $100 \%$ of

506 users on $06 / 08 / 2020$. In this first app flow 425,657 participants completed the

507 questionnaire. After reviewing feedback from UK users, the app flow was altered to

508 limit participant burden and to reduce attrition. On 07/08/2020 a new question was

509 added after the participants had completed the first 'peri-pandemic'section asking

510 'Has your diet changed?'[Yes, No or Unsure]. If users answered 'yes'or 'unsure'

511 they were invited to complete the 'pre-pandemic 'section. If users answered 'no'the

512 app flow ended (Figure 5). 422,285 participants participated in the second flow. In

513 the US, the questionnaire was launched to $20 \%$ of users on $03 / 09 / 2020$, and $100 \%$

514 on $28 / 09 / 2020(n=80,306)$ via the second flow only. Mode completion time for both

515 sections was 14-16 minutes. Within the app, individuals reported their height and

516 weight in response to the questions "About how much do you weigh without shoes?"

517 and "About how tall are you without shoes?". These were converted (if necessary) to

518 kilograms and meters before calculating the BMI $\left(\mathrm{kg} / \mathrm{m}^{2}\right)$. Participant characteristics

519 are described in Supplementary Table 1.

520

521 Exclusions and cohort interaction analysis: Participants were excluded based on

522 the primary outcome $(\mathrm{BMI})$ if: $(1)<2$ or $>98$ th percentile (excluding 0$)$ for weight $(\mathrm{kg})$

523 and height (cm); (2) pregnant; (3) > 98 percentile for free text options sleep, fruit and

524 vegetable portions, number of meals and number of snacks (excluding 0); (4) both 
525 questionnaire sections left incomplete (Supplementary Table 7). Participants were

526 divided into cohorts relative to the flow of the app (Figure 5), and by country. The

527 discovery cohort $(n=425,657)$ from the first flow, the UK validation cohort

$528(\mathrm{n}=422,285)$ from the second flow ( Has your diet changed), and the US replication

529 cohort $(n=14,366)$. A sensitivity analysis was performed to assess significant

530 population differences between the discovery and validation cohort. Researchers

531 defined 'change 'and 'no change 'groups within both cohorts relative to a $>1$ point

532 multi-directional change in diet quality score (no change; $\leq 1$ and $\geq-1$ ). Demographic

533 characteristics were compared between the 'change 'and 'no change 'groups

534 (Supplementary Table 2). The interaction was plotted between the primary outcome

535 (BMI) and the primary exposure (DQS). To minimise bias, all analyses in this study

536 were performed using the discovery cohort. Disruption index as well as diet and

537 lifestyle pattern analyses were replicated in the UK validation and the US replication 538 cohorts.

539

540

541 


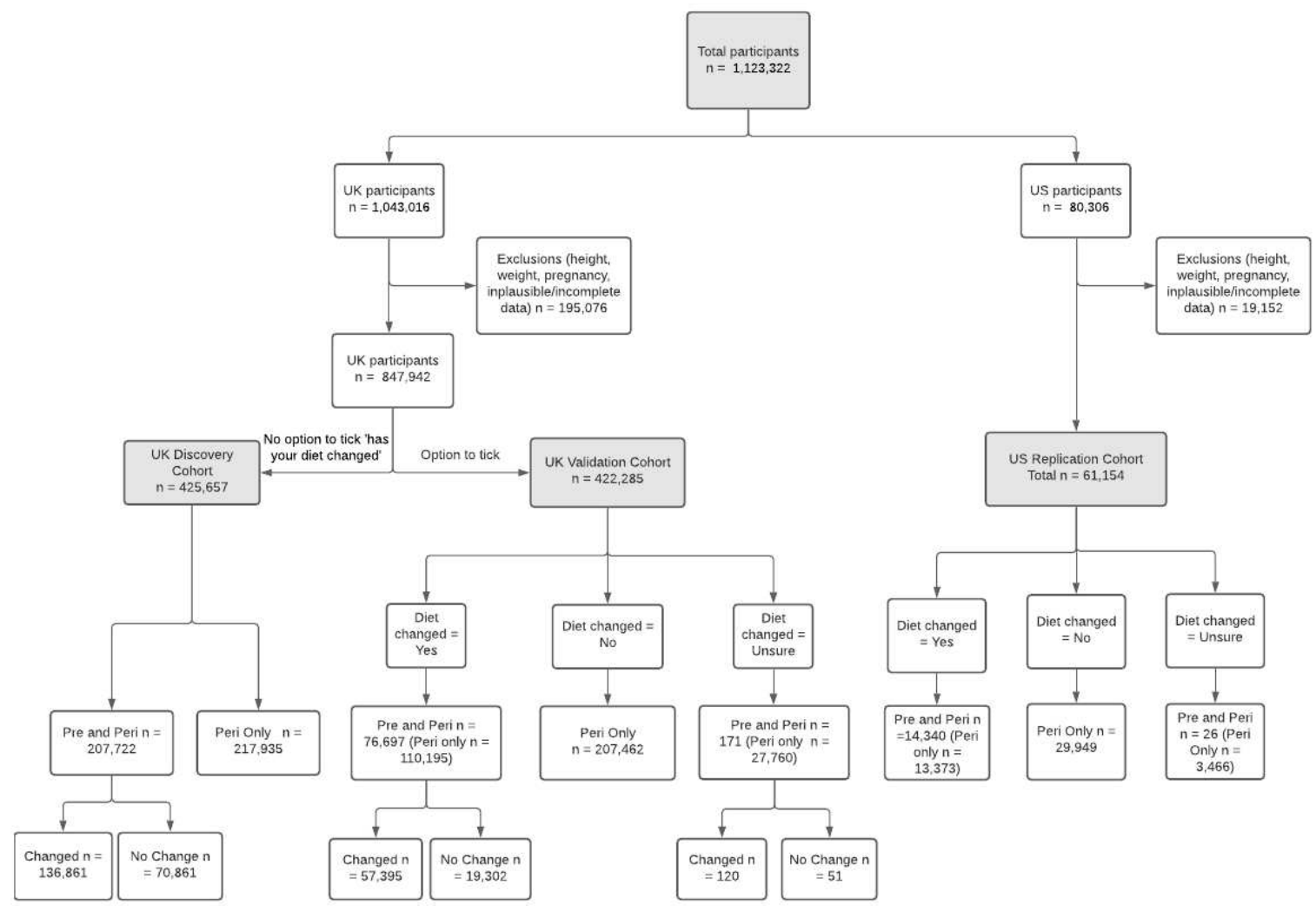

Figure 5. Consort Diagram

546 Disruption Index: A novel diet and lifestyle disruption index (DI) was developed.

547 Domains sleep (weekdays), physical activity, diet (DQS and snacking frequency),

548 and alcohol intake frequency were selected based on commonality in previous

549 published healthy lifestyle scores ${ }^{48,49}$. A bi-directional 'change 'was determined as

550 one point for any change (either $+/-$ ) for each variable, with maximum disruption score as 5, and the minimum as 0 (Supplementary Table 3).

553 Pre and peri-pandemic comparisons: In the discovery cohort, and validated in the

554 UK validation cohort, the mean, SD, and 10th and 90th percentiles for 'pre-

555 pandemic 'and 'peri-pandemic', percentage change (between the two time-points), and the number of participants who increased/decreased was applied to the continuous and categorical variables (Supplementary Tables 4, 5, and 6). For 
continuous variables, the quantity of increase/decrease was also described. Change

in body weight, BMI, disruption index, physical activity, alcohol intake (units),

snacking, fruit and vegetable intake (combined) and diet quality was visualised

across UK geographical regions using python package geopandas v. 0.7.0. IMD was

estimated according to small geographical location, or neighbourhood, ranking areas according to multiple deprivation parameters (least deprived $=32844$, most deprived

$=1$ ). Further reference to deprivation throughout is related to IMD status ${ }^{24}$. Deciles for England, Wales and Northern Ireland were pre generated by the official data source ${ }^{24}$. For Scotland, the same deciles were applied by the research team.

Factor analysis: Factor analysis with orthogonal transformation (varimax procedure) was used to construct a distinct 'healthy 'diet and lifestyle pattern and an 'unhealthy ' dietary pattern (loadings and input variables depicted in Supplementary Table 8).

The dietary patterns were stratified into quartiles to compare demographic characteristics and body weight changes (Supplementary Table 9 and 10).

574 Structural equation modelling (SEM): SEM was used to describe the relationship of exposures of a change in sleep (weekends and weekdays), physical activity, diet (DQS and snacking frequency), and alcohol intake (frequency and quantity)

577 (Supplementary Table 11). Age was included in the model owing to its established 578 relationship with $\mathrm{BMI}^{32}$. Change in body weight was categorised as; (1) an absolute bi-directional change, (2) an increase in body weight, and (3) a decrease in body weight from 'pre-pandemic 'to 'peri-pandemic 'weight status. Further, stratified models were also developed based on a low and high IMD. The model was fitted

582 under a maximum likelihood framework using covariance matrices. Relative model fit 
583 was assessed using the comparative fit index ( 0 no fit; 1 perfect fit) ${ }^{50}$, and the

584 absolute fit by the root mean square error of approximation. Statistical analysis was

585 performed using SPSS (IBM Corp, Armonk, NY, USA), R (v 3.5.1), AMOS and

586 ExeTera.

587

588 Ethics

589 The King's College London Ethics Committee approved the ethics for the app, and

590 all users provided consent for non-commercial use. An informal consultation with

591 TwinsUK members over email and social media before the app was launched found

592 that they were overwhelmingly supportive of the project. The US protocol was

593 approved by the Partners Human Research Committee.

594

595 Data availability

596 Data collected in the app are being shared with other health researchers through the

597 NHS-funded Health Data Research UK (HDRUK)/SAIL consortium, housed in the

598 UK Secure e-Research Platform (UKSeRP) in Swansea. Data from the Diet and

599 Lifestyle Questionnaire can be made available by application to TREC at the

600 Department of Twins Research and Epidemiology at King's College London. US

601 investigators are encouraged to coordinate data requests through the COPE

602 Consortium (www.monganinstitute.org/cope-consortium). Data updates can be found 603 at https://covid.joinzoe.com.

604

605

606 
608 The app code is publicly available from https://github.com/zoe/covid-tracker-react-

609 native.

610

\section{Acknowledgements}

612 We express our sincere thanks to all of the participants who entered data into the

613 app, including study volunteers enrolled in cohorts within the Coronavirus Pandemic

614 Epidemiology (COPE) consortium. We thank the staff of Zoe Global and the

615 Department of Twin Research at King's College London for tireless work in

616 contributing to the running of the study and data collection. We also thank Professor

617 Janet Cade, Leeds University, for her feedback on the manuscript.

\section{Author contributions}

620 Conceptualization: SEB, TDS, JW, SO, CS; Data Curation: BM, MM; Formal

621 Analysis: BM, MM, PF, LN, JM, RG, ERL, AC, MG; Investigation: SS, CH, ERL,

622 SEB, RG, MM, PF, AC, JM, LM, CG; Supervision: SEB; Writing of the Manuscript:

$623 \mathrm{MM}, \mathrm{ERL}, \mathrm{JM}, \mathrm{LN}, \mathrm{SS}, \mathrm{KK}, \mathrm{BM}, \mathrm{TM}, \mathrm{MG}, \mathrm{CS}, \mathrm{JW}, \mathrm{CH}, \mathrm{DD}, \mathrm{CS}, \mathrm{SO}, \mathrm{CG}, \mathrm{TDS}, \mathrm{AC}$, 624 PF, RG, SEB.

627 This work was supported by Zoe Global. The Department of Twin Research receives

628 grants from the Wellcome Trust (212904/Z/18/Z) and Medical Research

629 Council/British Heart Foundation Ancestry and Biological Informative Markers for 
630 Stratification of Hypertension (AIMHY; MR/M016560/1), and support from the

631 European Union, the Chronic Disease Research Foundation, Zoe Global, the NIHR

632 Clinical Research Facility and the Biomedical Research Centre (based at Guy's and

633 St Thomas 'NHS Foundation Trust in partnership with King's College London). PWF, 634 ATC, and ERL are consultants to Zoe Global Ltd ("Zoe"). TDS, SEB, JW, GH, SS,

$635 \mathrm{CH}$ and $\mathrm{KK}$ are or have been employees of Zoe. Other authors have no conflict of 636 interest to declare. The study sponsors (Zoe Global Ltd; JW and GH) contributed as 637 part of the Scientific Advisory Board in the study design and collection.

\section{References}

1. Groarke, J. M. et al. Loneliness in the UK during the COVID-19 pandemic: Cross-sectional results from the COVID-19 Psychological Wellbeing Study. PLoS One 15, e0239698 (2020).

2. Hwang, T.-J., Rabheru, K., Peisah, C., Reichman, W. \& Ikeda, M. Loneliness and social isolation during the COVID-19 pandemic. Int. Psychogeriatr. 32, 1217-1220 (2020).

3. Bell, T., Gardiner, L. \& Tomlinson, D. Getting Britain Working (Safely) Again: The Next Phase of the Coronavirus Job Retention Scheme. London: Resolution Foundation (2020).

4. Mardones, F. O. et al. The COVID-19 Pandemic and Global Food Security. Front Vet Sci 7, 578508 (2020).

5. Deschasaux-Tanguy, M. et al. Diet and physical activity during the COVID-19 lockdown period (March-May 2020): results from the French NutriNet-Sante cohort study. medRxiv (2020). 
6. Renzo, L. D. et al. Eating habits and lifestyle changes during COVID-19 lockdown: an Italian survey. Journal of Translational Medicine vol. 18 (2020).

7. Sidor, A. \& Rzymski, P. Dietary Choices and Habits during COVID-19 Lockdown: Experience from Poland. Nutrients 12, (2020).

8. Just-Østergaard, E., Mortensen, E. L. \& Flensborg-Madsen, T. Major life events and risk of alcohol use disorders: a prospective cohort study. Addiction 113, 2533 (2018).

9. Rowshan Ravan, A., Bengtsson, C., Lissner, L., Lapidus, L. \& Björkelund, C. Thirty-six-year secular trends in sleep duration and sleep satisfaction, and associations with mental stress and socioeconomic factors--results of the Population Study of Women in Gothenburg, Sweden. J. Sleep Res. 19, 496-503 (2010).

10. Li, Y. et al. Relationship Between Stressful Life Events and Sleep Quality: Rumination as a Mediator and Resilience as a Moderator. Front. Psychiatry 10, 348 (2019).

11. Sims, R. et al. Perceived stress and eating behaviours in a community-based sample of African Americans. Eat. Behav. 9, 137-142 (2008).

12. Schweren, L. J. S. et al. Diet quality, stress and common mental health problems: A cohort study of 121,008 adults. Clin. Nutr. (2020) doi:10.1016/j.clnu.2020.06.016.

13. Stults-Kolehmainen, M. A. \& Sinha, R. The effects of stress on physical activity and exercise. Sports Med. 44, 81-121 (2014).

14. Geiker, N. R. W. et al. Does stress influence sleep patterns, food intake, weight gain, abdominal obesity and weight loss interventions and vice versa? Obes. Rev. 19, 81-97 (2018). 
15. Mehlig, K. et al. Negative life events predict weight gain in a 13-year follow-up of an adult Swedish population. J. Psychosom. Res. 132, 109973 (2020).

16. Daivadanam, M. et al. Lifestyle change in Kerala, India: needs assessment and planning for a community-based diabetes prevention trial. BMC Public Health 13, 95 (2013).

17. Wing, R. R. \& Phelan, S. Long-term weight loss maintenance. Am. J. Clin. Nutr. 82, 222S-225S (2005).

18. Fothergill, E. et al. Persistent metabolic adaptation 6 years after 'The Biggest Loser 'competition. Obesity 24, 1612-1619 (2016).

19. González-Muniesa, P. et al. Obesity. Nat Rev Dis Primers 3, 17034 (2017).

20. Gill, T. Importance of preventing weight gain in adulthood. Asia Pac. J. Clin. Nutr. 11 Suppl 3, S632-6 (2002).

21. WHO | Obesity: preventing and managing the global epidemic. (2015).

22. Naja, F. \& Hamadeh, R. Nutrition amid the COVID-19 pandemic: a multi-level framework for action. Eur. J. Clin. Nutr. 74, 1117-1121 (2020).

23. Drew, D. A. et al. Rapid implementation of mobile technology for real-time epidemiology of COVID-19. Science 368, 1362-1367 (2020).

24. Ministry of Housing \& Communities \& Local Government. English indices of deprivation 2015. (2015).

25. Cleghorn, C. L. et al. Can a dietary quality score derived from a short-form FFQ assess dietary quality in UK adult population surveys? Public Health Nutr. 19, 2915-2923 (2016).

26. Yin, J. et al. Relationship of Sleep Duration With All-Cause Mortality and Cardiovascular Events: A Systematic Review and Dose-Response MetaAnalysis of Prospective Cohort Studies. J. Am. Heart Assoc. 6, (2017). 
27. Aune, D. et al. Fruit and vegetable intake and the risk of cardiovascular disease, total cancer and all-cause mortality-a systematic review and dose-response meta-analysis of prospective studies. Int. J. Epidemiol. 46, 1029-1056 (2017).

28. Wood, A. M. et al. Risk thresholds for alcohol consumption: combined analysis of individual-participant data for 599912 current drinkers in 83 prospective studies. Lancet 391, 1513-1523 (2018).

29. Kyu, H. H. et al. Physical activity and risk of breast cancer, colon cancer, diabetes, ischemic heart disease, and ischemic stroke events: systematic review and dose-response meta-analysis for the Global Burden of Disease Study 2013. BMJ 354, i3857 (2016).

30. Wang, Y.-Q. et al. Increased Eating Frequency Is Associated with Lower Obesity Risk, But Higher Energy Intake in Adults: A Meta-Analysis. Int. J. Environ. Res. Public Health 13, (2016).

31. O'Connor, L., Brage, S., Griffin, S. J., Wareham, N. J. \& Forouhi, N. G. The cross-sectional association between snacking behaviour and measures of adiposity: the Fenland Study, UK. Br. J. Nutr. 114, 1286-1293 (2015).

32. Lloyd-Sherlock, P. et al. Population ageing and health. Lancet 379, 1295-1296 (2012).

33. Wang, X. et al. Fruit and vegetable consumption and mortality from all causes, cardiovascular disease, and cancer: systematic review and dose-response meta-analysis of prospective cohort studies. BMJ 349, g4490 (2014).

34. Women shoulder the responsibility of 'unpaid work'. https://www.ons.gov.uk/employmentandlabourmarket/peopleinwork/earningsand workinghours/articles/womenshouldertheresponsibilityofunpaidwork/2016-11-10 (2016). 
35. Deschasaux-Tanguy, M. et al. Diet and physical activity during the COVID-19 lockdown period (March-May 2020): results from the French NutriNet-Santé cohort study. medRxiv 2020.06.04.20121855 (2020) doi:10.1101/2020.06.04.20121855.

36. Deschasaux-Tanguy, M. et al. Diet and physical activity during the COVID-19 lockdown period (March-May 2020): results from the French NutriNet-Santé cohort study. medRxiv 2020.06.04.20121855 (2020) doi:10.1101/2020.06.04.20121855.

37. Afp. How coronavirus lockdown will make us fatter. Daily mail (2020).

38. Clemmensen, C., Petersen, M. B. \& Sørensen, T. I. A. Will the COVID-19 pandemic worsen the obesity epidemic? Nat. Rev. Endocrinol. 16, 469-470 (2020).

39. Kalligeros, M. et al. Association of Obesity with Disease Severity Among Patients with Coronavirus Disease 2019. Obesity vol. 28 1200-1204 (2020).

40. Goossens, G. H. et al. Obesity and COVID-19: A Perspective from the European Association for the Study of Obesity on Immunological Perturbations, Therapeutic Challenges, and Opportunities in Obesity. Obes. Facts 13, 439-452 (2020).

41. Hruby, A. \& Hu, F. B. The Epidemiology of Obesity: A Big Picture. Pharmacoeconomics 33, 673-689 (2015).

42. Laurencin, C. T. \& McClinton, A. The COVID-19 Pandemic: a Call to Action to Identify and Address Racial and Ethnic Disparities. J Racial Ethn Health Disparities 7, 398-402 (2020).

43. Rehm, C. D., Peñalvo, J. L., Afshin, A. \& Mozaffarian, D. Dietary Intake Among US Adults, 1999-2012. JAMA 315, 2542-2553 (2016). 
44. Power, M., Doherty, B., Pybus, K. \& Pickett, K. How COVID-19 has exposed inequalities in the UK food system: The case of UK food and poverty. Emerald Open Research 2, (2020).

45. Bhutani, S., Kahn, E., Tasali, E. \& Schoeller, D. A. Composition of two-week change in body weight under unrestricted free-living conditions. Physiol Rep 5, (2017).

46. Magkos, F. et al. Effects of Moderate and Subsequent Progressive Weight Loss on Metabolic Function and Adipose Tissue Biology in Humans with Obesity. Cell Metab. 23, 591-601 (2016).

47. Nguyen, L. H. et al. Risk of COVID-19 among front-line health-care workers and the general community: a prospective cohort study. Lancet Public Health $\mathbf{5}$, e475-e483 (2020).

48. Díaz-Gutiérrez, J., Ruiz-Canela, M., Gea, A., Fernández-Montero, A. \& Martínez-González, M. Á. Association Between a Healthy Lifestyle Score and the Risk of Cardiovascular Disease in the SUN Cohort. Rev. Esp. Cardiol. 71, $1001-1009$ (2018).

49. Sotos-Prieto, M. et al. A Healthy Lifestyle Score Is Associated with Cardiometabolic and Neuroendocrine Risk Factors among Puerto Rican Adults. J. Nutr. 145, 1531-1540 (2015).

50. Shi, D., Lee, T. \& Maydeu-Olivares, A. Understanding the Model Size Effect on SEM Fit Indices. Educ. Psychol. Meas. 79, 310-334 (2019) 


\section{Supplements:}

Supplementary tables:

https://drive.google.com/file/d/1cvWjMW3IDYM4qtUbZfv8rvXYkR35J-

cb/view?usp=sharing

\section{App flow:}

https://docs.google.com/document/d/1kgNHjCXUD16cKn8zMRAngHXk sSE b eH4 T26s5Cly0/edit?usp=sharing 
Figures

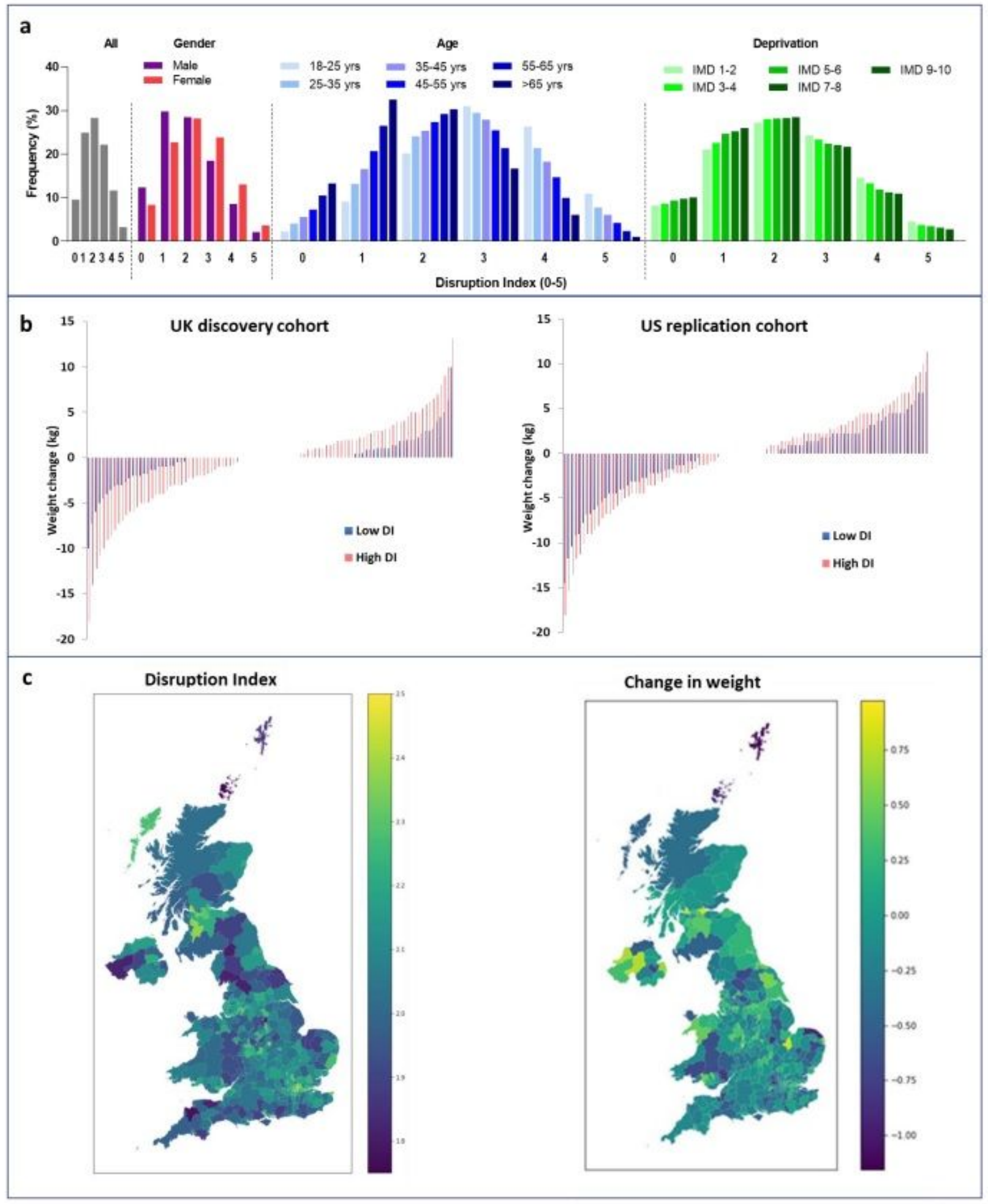

Figure 1

Disruption Index population distribution and weight change. a. Community-level disruption Index on a scale of 0-5 including 5 domains (Diet Quality Score, snacking frequency, alcohol intake frequency, physical activity and weekday sleep duration), stratified according to sex, age and multiple deprivation 
index based on residence (IMD) in the UK cohort. b. Change in body weight during the pandemic (pre minus peri-pandemic values) stratified according to low $(\leq 1)$ or high $(\geq 4)$ disruption index in the UK discovery and US replication cohort. c. Geographical distribution of disruption index and change in weight in the UK discovery cohort.
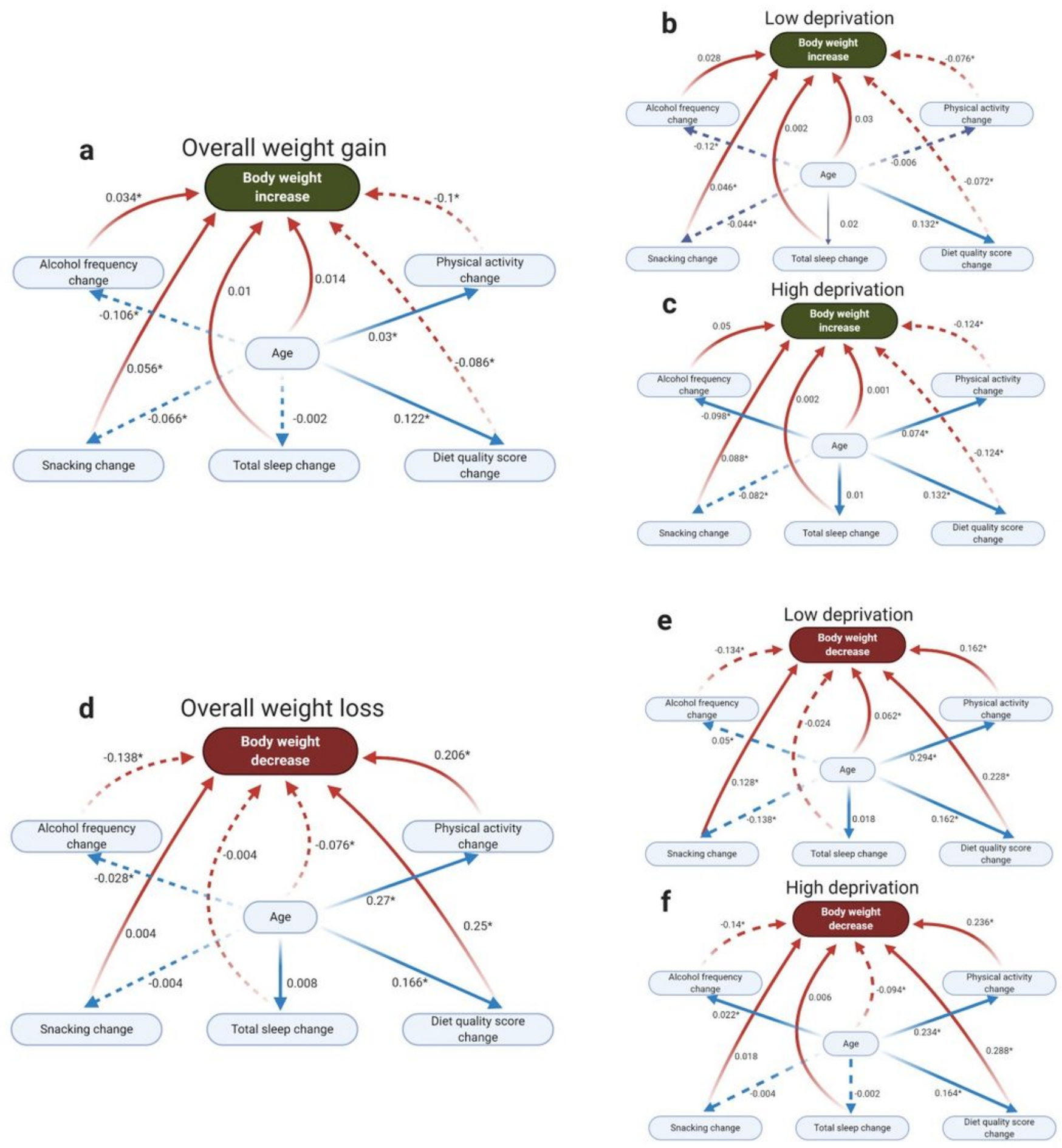

Figure 2 
Association between diet and lifestyle and change in weight pre- to peri-pandemic. Structural equation modelling (SEM) showing the associations between exposures identified by machine learning and outcome (body weight increase/decrease). a. overall increase, b. body weight increase in the high IMD (IMD8-10) sub-population, c. body weight increase in the low IMD (IMD1-3) sub-population, d. overall decreased body weight, e. body weight decrease in high IMD (IMD8-10) sub-population, f. body weight decrease in low IMD (IMD1-3) sub-population. Blue arrows represent indirect effects on body weight. Red arrows represent direct effects on body weight. Dashed arrows represent inverse 2effects on body weight. Numbers represent strength of association (standardised $B$ coefficients). *significant at $P<0.05$. Full dataset seen in Supplementary Table 5.
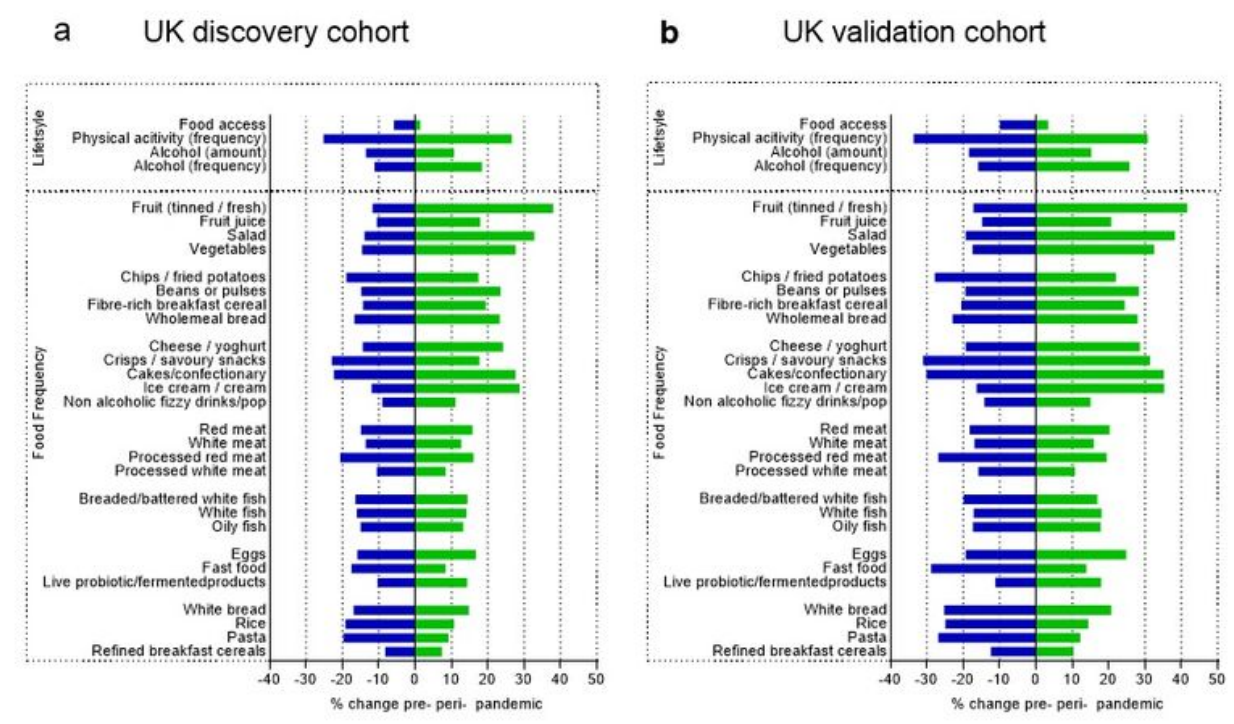

c US replication cohort

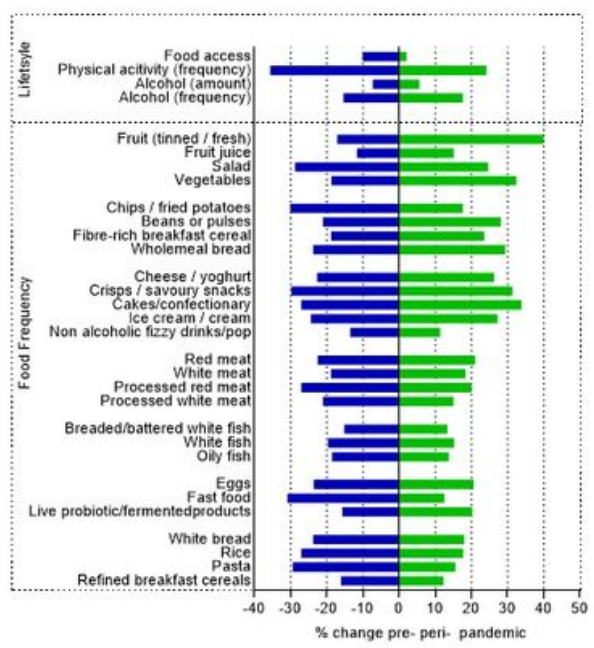

\section{Figure 3}

Proportion of the population changing frequency of intake of food groups and behaviours. Percentage of cohort that changed (increase/decreased) the frequency of dietary intake and lifestyle behaviours from pre- to peri-pandemic, obtained from the amended Leeds Short Form Food Frequency Questionnaire and others, in the a) UK discovery b) UK validation and c) US replication cohorts. 


\section{a}

UK healthy pattern

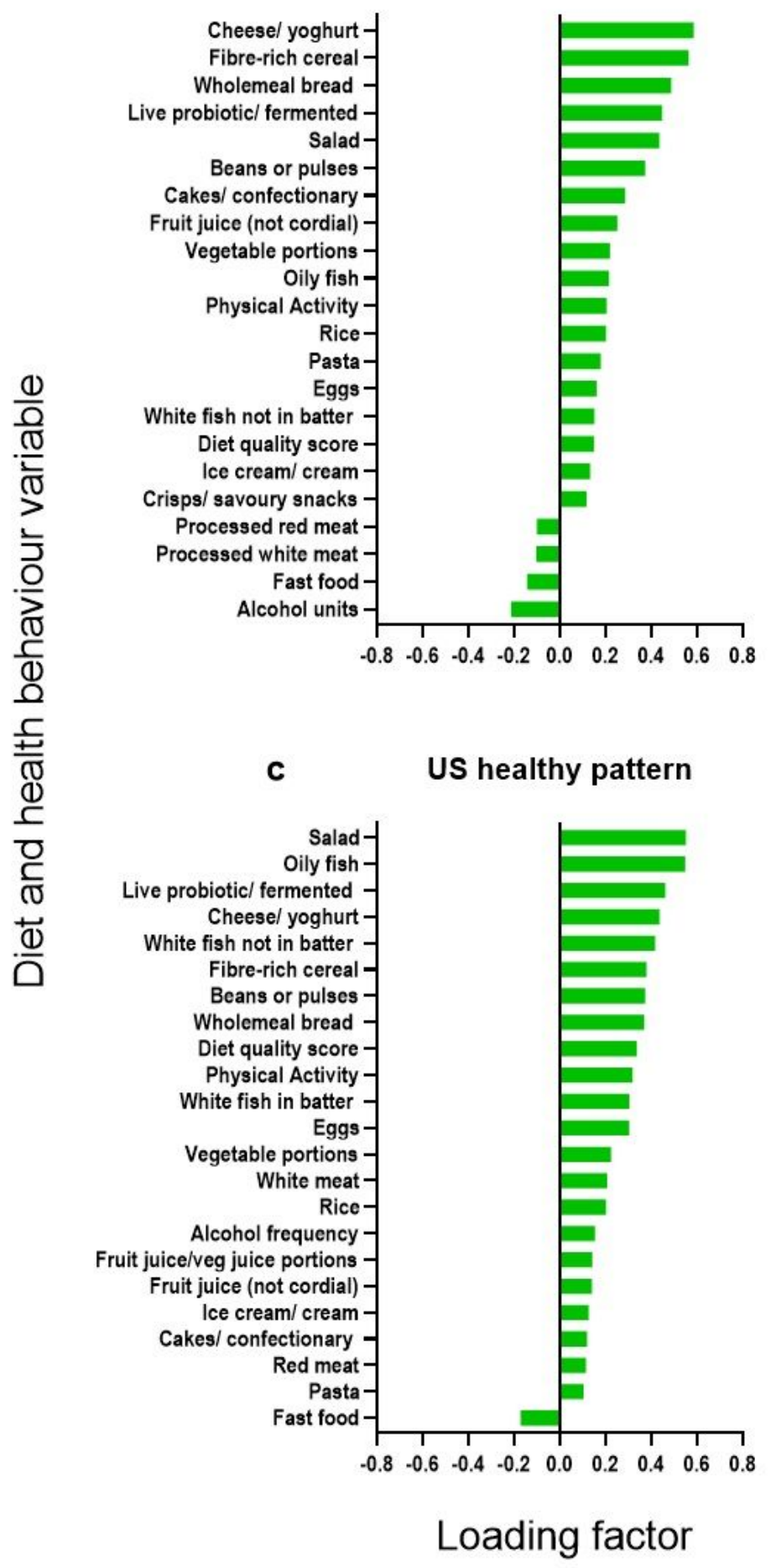

b

UK unhealthy pattern

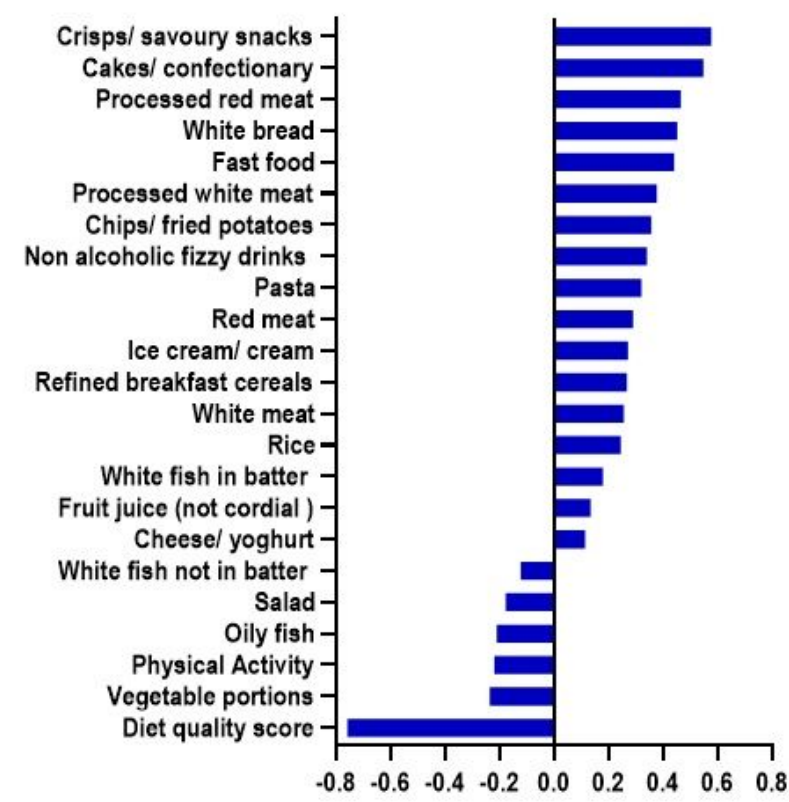

d US unhealthy pattern

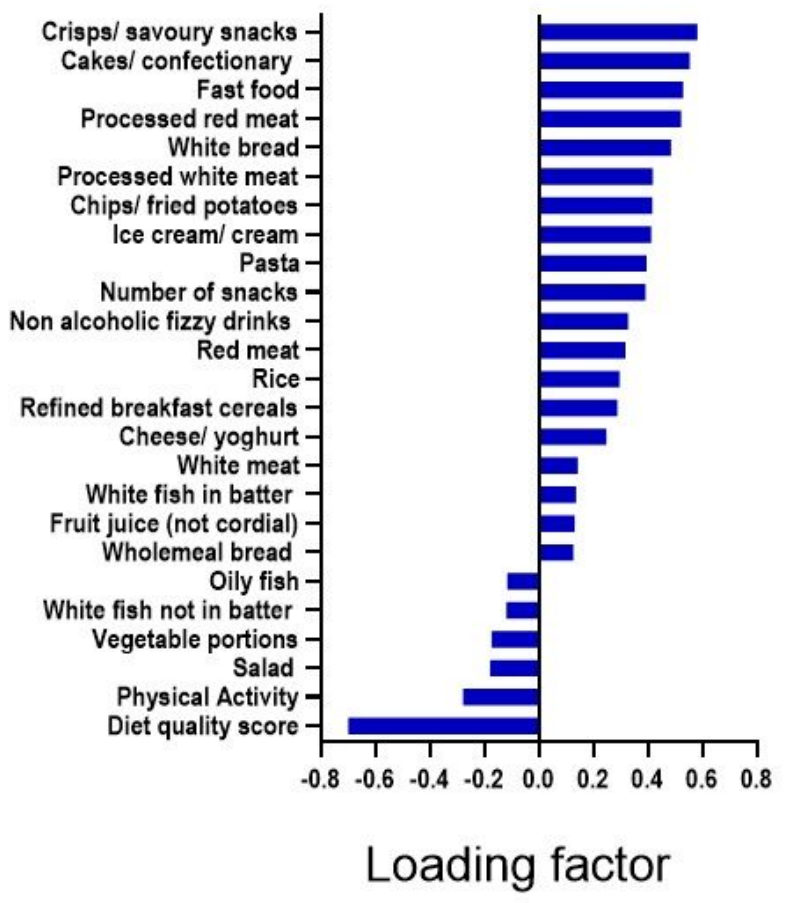

\section{Figure 4}

Loadings of diet and health behaviour variables to 'healthy 'and 'unhealthy' clusters. Loadings $(\geq 0.1)$ for 'healthy '(a) and 'unhealthy '(b) patterns in the UK discovery and 'healthy '(c) and 'unhealthy '(d) patterns in the US replication cohort. Full breakdown of the loading of each dietary and health behaviour variable for the 'healthy 'and 'unhealthy ' pattern can be seen in Supplementary Table 8. 


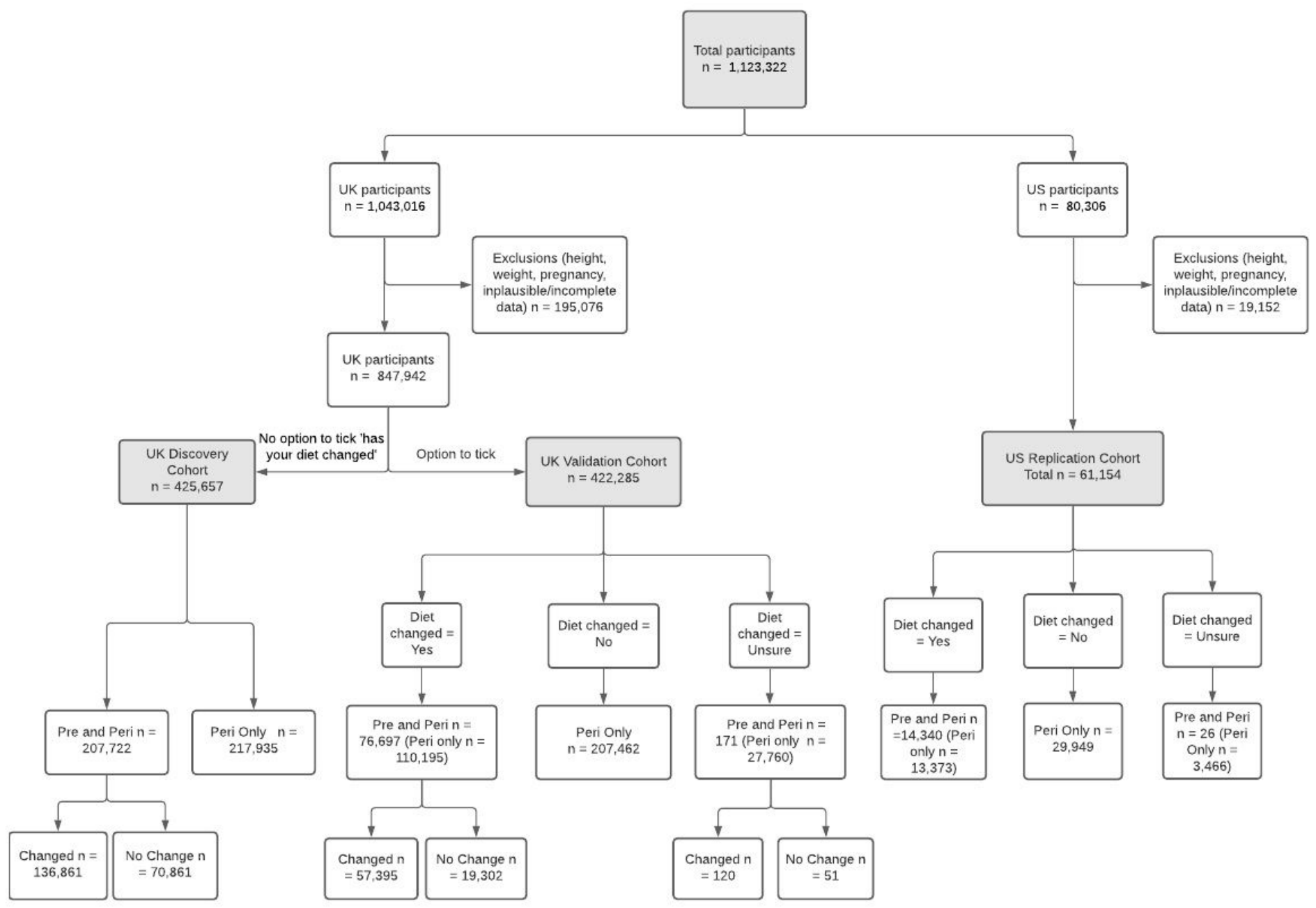

Figure 5

Consort Diagram

\section{Supplementary Files}

This is a list of supplementary files associated with this preprint. Click to download.

- BerryDietCovidsupplementarytablesNatureFood2ndFeb.xlsx

- DietStudyFlow2.pdf 